\title{
Article
}

\section{Heat Priming of Lentil (Lens culinaris Medik.) Seeds and Foliar Treatment with $\gamma$-Aminobutyric Acid (GABA), Confers Protection to Reproductive Function and Yield Traits under High-Temperature Stress Environments}

\author{
Anjali Bhardwaj ${ }^{1}$, Kumari Sita ${ }^{1}$, Akanksha Sehgal ${ }^{1,2}{ }^{2}$, Kalpna Bhandari ${ }^{1}$, Shiv Kumar ${ }^{3}$ (D, P. V. Vara Prasad ${ }^{4}{ }^{(D}$,

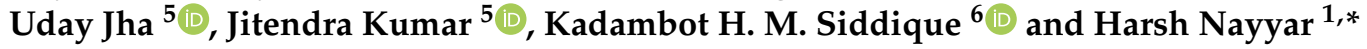 \\ 1 Department of Botany, Panjab University, Chandigarh 160014, India; bhardwajanjali96@gmail.com (A.B.); \\ sitas191@gmail.com (K.S.); as5002@msstate.edu (A.S.); kalpna.bhandari@gmail.com (K.B.) \\ 2 Department of Plant and Soil Sciences, Mississippi State University, Starkville, MS 39762, USA \\ 3 Biodiversity and Crop Improvement Program, International Center for Agricultural Research in the Dry \\ Areas (ICARDA), Rabat 10112, Morocco; sk.agrawal@cgiar.org \\ 4 Department of Agronomy, Kansas State University, Manhattan, KS 66506, USA; vara@ksu.edu \\ check for \\ updates \\ Citation: Bhardwaj, A.; Sita, K.; \\ Sehgal, A.; Bhandari, K.; Kumar, S.; \\ 5 Crop Improvement Division, Indian Institute of Pulses Research, Kanpur, Uttar Pradesh 208024, India; \\ u9811981@gmail.com (U.J.); jitendra73@gmail.com (J.K.) \\ 6 The UWA Institute of Agriculture, The University of Western Australia, Perth, WA 6009, Australia; \\ kadambot.siddique@uwa.edu.au \\ * Correspondence: harshnayyar@hotmail.com
} Prasad, P.V.V.; Jha, U.; Kumar, J.; Siddique, K.H.M.; Nayyar, H. Heat Priming of Lentil (Lens culinaris Medik.) Seeds and Foliar Treatment with $\gamma$-Aminobutyric Acid (GABA), Confers Protection to Reproductive Function and Yield Traits under High-Temperature Stress Environments. Int. J. Mol. Sci. 2021, 22, 5825. https://doi.org/10.3390/ ijms22115825

Academic Editors: Giampiero Cai, Luigi Parrotta and Lavinia Mareri

Received: 6 May 2021

Accepted: 26 May 2021

Published: 29 May 2021

Publisher's Note: MDPI stays neutral with regard to jurisdictional claims in published maps and institutional affiliations.

Copyright: () 2021 by the authors. Licensee MDPI, Basel, Switzerland. This article is an open access article distributed under the terms and conditions of the Creative Commons Attribution (CC BY) license (https:// creativecommons.org/licenses/by/ $4.0 /)$.

\begin{abstract}
Gradually increasing temperatures at global and local scales are causing heat stress for cool and summer-season food legumes, such as lentil (Lens culinaris Medik.), which is highly susceptible to heat stress, especially during its reproductive stages of development. Hence, suitable strategies are needed to develop heat tolerance in this legume. In the present study, we tested the effectiveness of heat priming $\left(\mathrm{HPr} ; 6 \mathrm{~h}\right.$ at $35^{\circ} \mathrm{C}$ ) the lentil seeds and a foliar treatment of $\gamma$-aminobutyric acid (GABA; $1 \mathrm{mM}$; applied twice at different times), singly or in combination (HPr+GABA), under heat stress $\left(32 / 20^{\circ} \mathrm{C}\right)$ in two heat-tolerant (HT; IG2507, IG3263) and two heat-sensitive (HS; IG2821, IG2849) genotypes to mitigate heat stress. The three treatments significantly reduced heat injury to leaves and flowers, particularly when applied in combination, including leaf damage assessed as membrane injury, cellular oxidizing ability, leaf water status, and stomatal conductance. The combined HPr+GABA treatment significantly improved the photosynthetic function, measured as photosynthetic efficiency, chlorophyll concentration, and sucrose synthesis; and significantly reduced the oxidative damage, which was associated with a marked up-regulation in the activities of enzymatic antioxidants. The combined treatment also facilitated the synthesis of osmolytes, such as proline and glycine betaine, by upregulating the expression of their biosynthesizing enzymes (pyrroline-5-carboxylate synthase; betaine aldehyde dehydrogenase) under heat stress. The HPr+GABA treatment caused a considerable enhancement in endogenous levels of GABA in leaves, more so in the two heat-sensitive genotypes. The reproductive function, measured as germination and viability of pollen grains, receptivity of stigma, and viability of ovules, was significantly improved with combined treatment, resulting in enhanced pod number (21-23\% in HT and 35-38\% in HS genotypes, compared to heat stress alone) and seed yield per plant (22-24\% in HT and 37-40\% in HS genotypes, in comparison to heat stress alone). The combined treatment ( $\mathrm{HPr}+\mathrm{GABA})$ was more effective and pronounced in heat-sensitive than heat-tolerant genotypes for all the traits tested. This study offers a potential solution for tackling and protecting heat stress injury in lentil plants.
\end{abstract}

Keywords: high temperature; legumes; lentil; pollen; pods; seeds; stress 


\section{Introduction}

Air temperatures are rising at both global and local scale, causing heat stress in many cool and summer season food crops and reducing their production potential [1,2]. Heat stress inhibits the growth and development of various food crops by altering several physiological and biochemical processes, which impairs crop performance [2,3]. At the vegetative stage, heat stress causes leaf chlorosis, necrosis, and accelerated phenology, and damages leaf tissue due to membrane injury, denatured proteins, oxidative damage, and dehydration [3]. At the reproductive stage, heat stress severely impacts the plants by disrupting pollen and stigma function and resulting in the lower seed set percentage [2,4]. The process of fertilization is impacted because of obstruction in pollen development, germination, and tube growth, resulting in pod set failure in different food grain and legumes crops $[2,5,6]$.

Lentil (Lens culinaris Medik.) is grown as a winter-season food legume and is highly susceptible to heat stress [7]. Lentil requires lower temperatures during vegetative growth and warmer temperatures lead up to maturity; $18-30{ }^{\circ} \mathrm{C}$ is considered as its optimum temperature range $[8,9]$. Lentil is cultivated on large areas in comparatively warmer parts of central and southern India, where supra-optimal temperatures, especially at the time of reproductive stage, significantly inhibit its yield potential. Moreover, global climate changes have shortened the cold period and lengthened the heat periods, further exposing winter-season crops to heat stress. In 2009 , a heat wave $\left(35^{\circ} \mathrm{C}\right.$ for six days) in southeastern Australia decreased lentil yields by $70 \%$ [10]. In Australia, temperatures more than $32 / 20^{\circ} \mathrm{C}(\mathrm{max} / \mathrm{min})$ in course of flowering and pod filling markedly reduced lentil seed yield and quality [10]. Hence, strategies are needed to impart heat tolerance in lentil.

Heat priming refers to a pre-treatment to plants at moderate temperature, which imparts tolerance to subsequent high temperature exposure in plants [11]. Heat priming can also be done to hydrating or germinating seeds. Some studies have indicated the potential benefits of heat priming during the early vegetative stage on plant performance during subsequent high temperature events, as in wheat (Triticum aestivum L.) [12], Arabidopsis [13], while another study reported no effect of heat priming on wheat performance [11]. Heat tolerance can also be improved with the application of growth-regulating molecules, such as salicylic acid, nitric oxide, polyamines, and others [14]. One of the promising molecules, $\gamma$-aminobutyric acid (GABA), a non-protein amino acid, has been shown to act as a signaling molecule in plants [15]. The involvement of GABA in plants exposed to various abiotic and biotic stresses has been reviewed recently [16], and the beneficial effects of GABA have been reported in the past [17-19]. Endogenous GABA levels changed in response to stress and influenced the defense mechanisms, pathways and processes [15]. GABA has been implicated in plant cell functioning, such as signaling, osmoregulation, cytosolic $\mathrm{pH}$ regulation, buffering in $\mathrm{C}$ and $\mathrm{N}$ metabolism, and oxidative stress protection [20,21]. Heat stress increased GABA levels and calcium-induced activation of glutamate decarboxylase [22]. GABA is involved in the sexual reproduction of angiosperms and is an essential amino acid for pollen fertility, and plays a vital role in the post-pollination fertilization process [23].

In the present study, we attempted heat-priming the hydrated lentil seeds along with a foliar GABA treatment to assess their effects on reducing the heat injury. Though, earlier studies have reported heat priming the plants at vegetative stages as an approach to induce subsequent stress tolerance, we tried this method on hydrated seeds in a controlled environment, to test its feasibility and to develop it as a technique to counter the effects of high temperature at later growth stages of lentil plants. The objective was to test the effectiveness of heat priming ( $\mathrm{HPr} ; 6 \mathrm{~h}$ at $35^{\circ} \mathrm{C}$ ) the lentil seeds and a foliar treatment of $\gamma$-aminobutyric acid (GABA; $1 \mathrm{mM}$; applied twice at different times), singly or in combination (HPr+GABA), under heat stress $\left(32 / 20^{\circ} \mathrm{C}\right)$ in two heat-tolerant (HT; IG2507, IG3263) and two heat-sensitive (HS; IG2821, IG2849) genotypes to mitigate heat stress. It was hypothesized that a short heat treatment of the hydrated seeds, when applied in combination with foliar GABA treatment, might enhance the heat tolerance in lentil. 
We probed their effects on several traits related to growth and yield, as well as defense mechanisms involving leaves and flowers.

\section{Results}

\subsection{Phenology}

Heat stress reduced the days to podding and maturity, more so in heat-sensitive (HS) than heat-tolerant $(\mathrm{HT})$ genotypes (Figure $1 \mathrm{~A}, \mathrm{~B})$. As a result, the flowering to podding and podding to maturity intervals (Figure 1C,D) also decreased significantly, compared to the controls. Heat priming (HPr) alone did not significant affect the phenology. The GABA treatment slightly increased days to flowering and podding and the intervals between different stages. The combined $\mathrm{HPr}+\mathrm{GABA}$ treatment was more effective at restoring phenology than their individual treatments. The heat-sensitive genotypes responded more to the combined treatment than the heat-tolerant genotypes, with significant improvements in the flowering-podding and podding-maturity intervals.
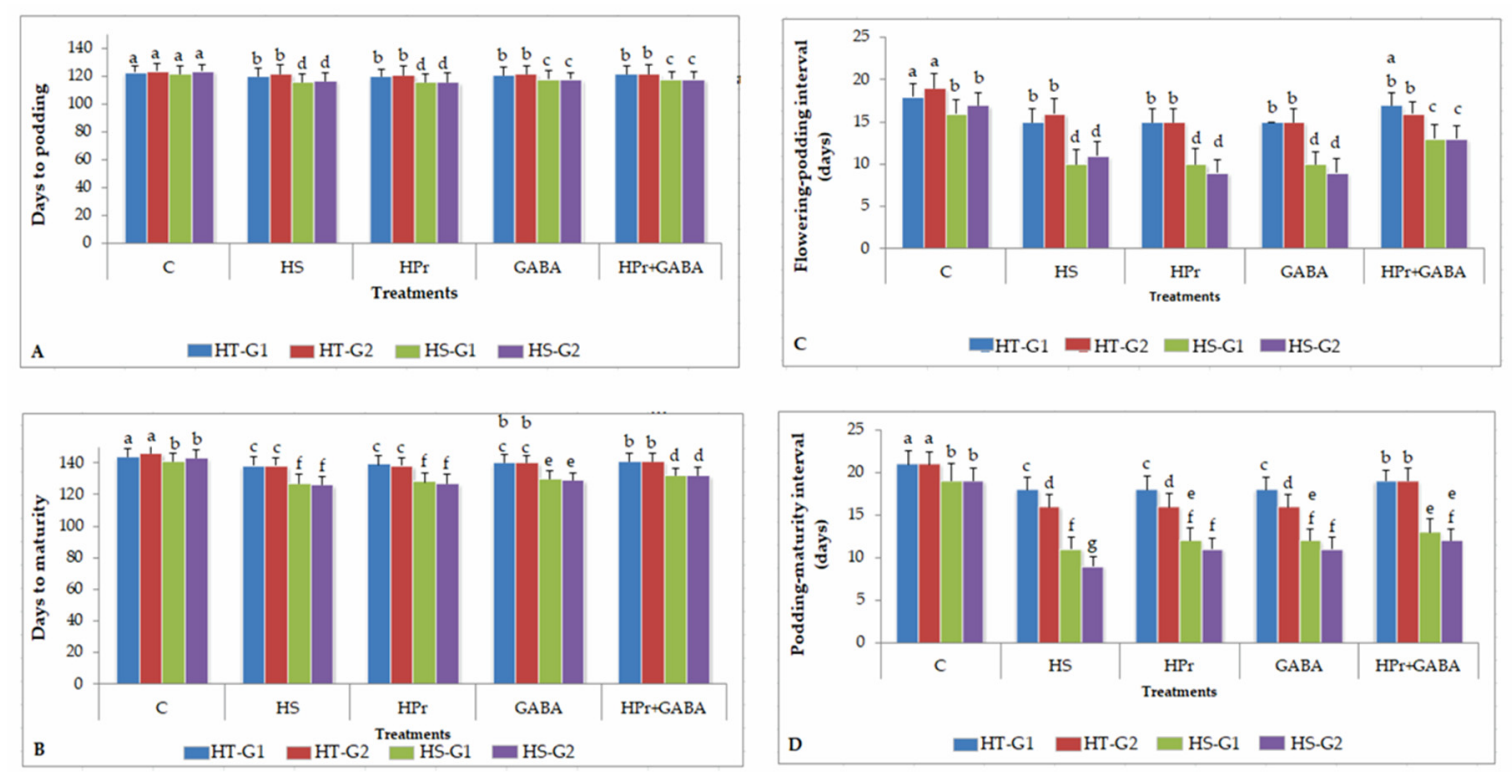

Figure 1. Phenology (Days to podding: (A); days to maturity: (B); flowering-podding interval: (C); podding-maturity interval: (D) of heat-tolerant (G1: IG2507; G2: IG3263) and heat-sensitive (G1: IG2821; G2: IG2849) genotypes in control $\left(28 / 18{ }^{\circ} \mathrm{C} ; 12 \mathrm{~h}\right.$ each), heat-stressed $\left(32 / 20^{\circ} \mathrm{C} ; 12 \mathrm{~h}\right.$ each), heat-primed (HPr), GABA-treated, and HPr+GABA treatments. Plants were exposed to heat stress at the onset of flowering (bud stage) for all genotypes; hence, the phenological data related to days to flowering is similar for all treatments. Vertical bars represent standard errors $(n=3)$. Different small letters on the bars indicate significant differences from each other $(p<0.05)$. LSD (least significant difference) for interaction (genotypes $\times$ stages $\times$ treatments) $(p<0.05)$ : Days to podding: 1.8; days to maturity: 1.9; flowering-podding interval: 1.8; podding-maturity interval: 1.7 .

\subsection{Stress Injury to Leaves}

\subsubsection{Membrane Damage}

The membrane damage as electrolyte leakage (EL) measurements (expressed as percentage) indicated that heat stress caused 19-20\% membrane damage during stage 1 and $20-23 \%$ damage during stage 2 in HT genotypes, with the corresponding values for HS genotypes being $19-22 \%$ and $28-29 \%$ (Figure 2A). The HPr and GABA treatments, applied alone, significantly reduced the membrane damage caused by heat stress, compared to control plants. The HPr+GABA treatment further reduced the membrane damage to about $15 \%$ during stage 1 in HT genotypes and 17\% in HS genotypes, and 16-18\% during stage 2 in HT genotypes and $19-20 \%$ in HS genotypes. 

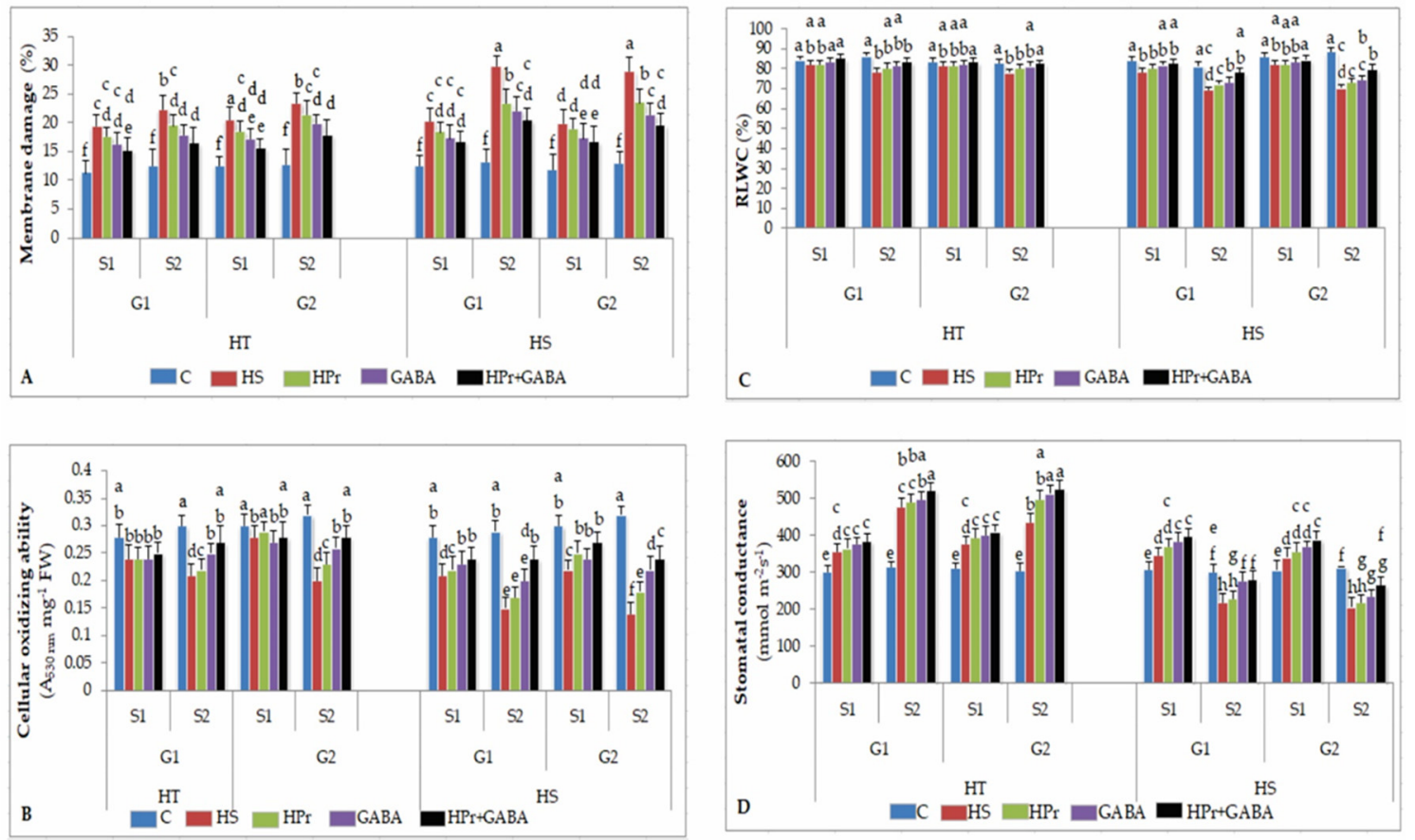

Figure 2. Effect of heat priming (HPr) and $\gamma$-amino butyric acid (GABA), applied individually or in combination (HPr+GABA) on membrane damage (A), cellular oxidizing ability (B), relative leaf water content, RLWC (C) and stomatal conductance (D) on heat-tolerant (G1: IG2507; G2: IG3263) and heat-sensitive (G1: IG2821; G2: IG2849) genotypes at stage 1 (S1) and stage 2 (S2) in heat-stressed (HS) lentil plants, compared to control (C). Vertical bars represent standard errors $(n=3)$. Different small letters on the bars indicate significant differences from each other $(p<0.05)$. LSD for interaction (genotypes $\times$ stages $\times$ treatments) $(p<0.05)$ : membrane damage: 2.9; cellular oxidizing ability: 0.030, relative leaf water content: 2.2 , stomatal conductance: 26.3 . FW = fresh weight.

\subsubsection{Cellular Oxidizing Ability}

Heat stress reduced cellular oxidizing ability by $6-16 \%$ in HT and $25-26 \%$ in HS genotypes during stage 1 and $30-38 \%$ in HT and $48-56 \%$ in HS genotypes during stage 2, compared to the respective controls (Figure 2B). Compared to heat stress, applied singly, HPr significantly increased the oxidizing ability during stage 2 in HS genotypes, while HT genotypes were less responsive at both stages. The GABA treatment increased cellular oxidizing ability by $19-30 \%$ during stage 2 in HT genotypes and $33-57 \%$ in HS genotypes, compared to heat stress applied singly. The HPr+GABA treatment further increased this trait, by $28-40 \%$ in HT and $60-71 \%$ in HS genotypes during stage 2 , in comparison to heat stress applied singly.

\subsubsection{Leaf Water Status}

Heat stress decreased leaf water status, recorded as relative leaf water content (RLWC; expressed as percentage), to $81.6-82.5 \%$ in HT and $78.4-82.3 \%$ in HS genotypes during stage 1, and $78.1-78.5 \%$ in HT and $69.4-70.4 \%$ in HS genotypes during stage 2, with reference to the controls (83.4-84.5\% in HT and $84.3-86.3 \%$ in HS genotypes during stage 1, 82.9-86.5\% in HT and 81.4-88.5\% in HS genotypes during stage 2) (Figure 2C). The HPr and GABA treatments alone significantly improved RLWC, especially in HS genotypes. The HPr+GABA treatment further improved RLWC to $83.4-85.3 \%$ in HT and $82.8-84.5$ in HS genotypes during stage 1 , and to $83 \%$ in HT and $78-80 \%$ in HS genotypes during stage 2.

\subsubsection{Stomatal Conductance}

Stomatal conductance $\left(\mathrm{g}_{\mathrm{s}}\right)$ increased with heat stress by $18-20 \%$ in HT and $11-12 \%$ in HS genotypes during stage 1, compared to control plants (Figure 2D). During stage 2, 
heat stress increased $\mathrm{g}_{\mathrm{s}}$ by $42-51 \%$ in HT genotypes, but decreased it by $27-34 \%$ in HS genotypes, in comparison to the controls. The HPr treatment slightly increased $g_{s}$ in both HS and HT genotypes, with reference to heat stress applied singly. The GABA treatment significantly increased $g_{s}$, more so during stage 2 , especially in HS genotypes, compared to heat stress alone. In the HPr+GABA treatment, $g_{s}$ increased more in HS (by $14-15 \%$ and $28-29 \%$ ) than HT genotypes (by 8-9\% and 10-21\%) during stage 1 and stage 2, respectively, with reference to heat stress applied singly.

\subsection{Reproductive Function}

\subsubsection{Pollen Germination}

Compared to pollen germination (PG; expressed as percentage) in control plants (87-89\% in HT and $83-88 \%$ in HS genotypes), heat stress reduced PG in HS genotypes (41-43\%) and HT genotypes (73-74\%) (Figure 3A). The HPr treatment improved PG, more so in HS (51-61\%) than HT genotypes (73-74\%). Similarly, the GABA treatment increased PG more in HS genotypes (65-67\%) than HT (76-78\%) genotypes. The HPr+GABA treatment increased PG to $70-73 \%$ in HS genotypes and $79-82 \%$ in HT genotypes.
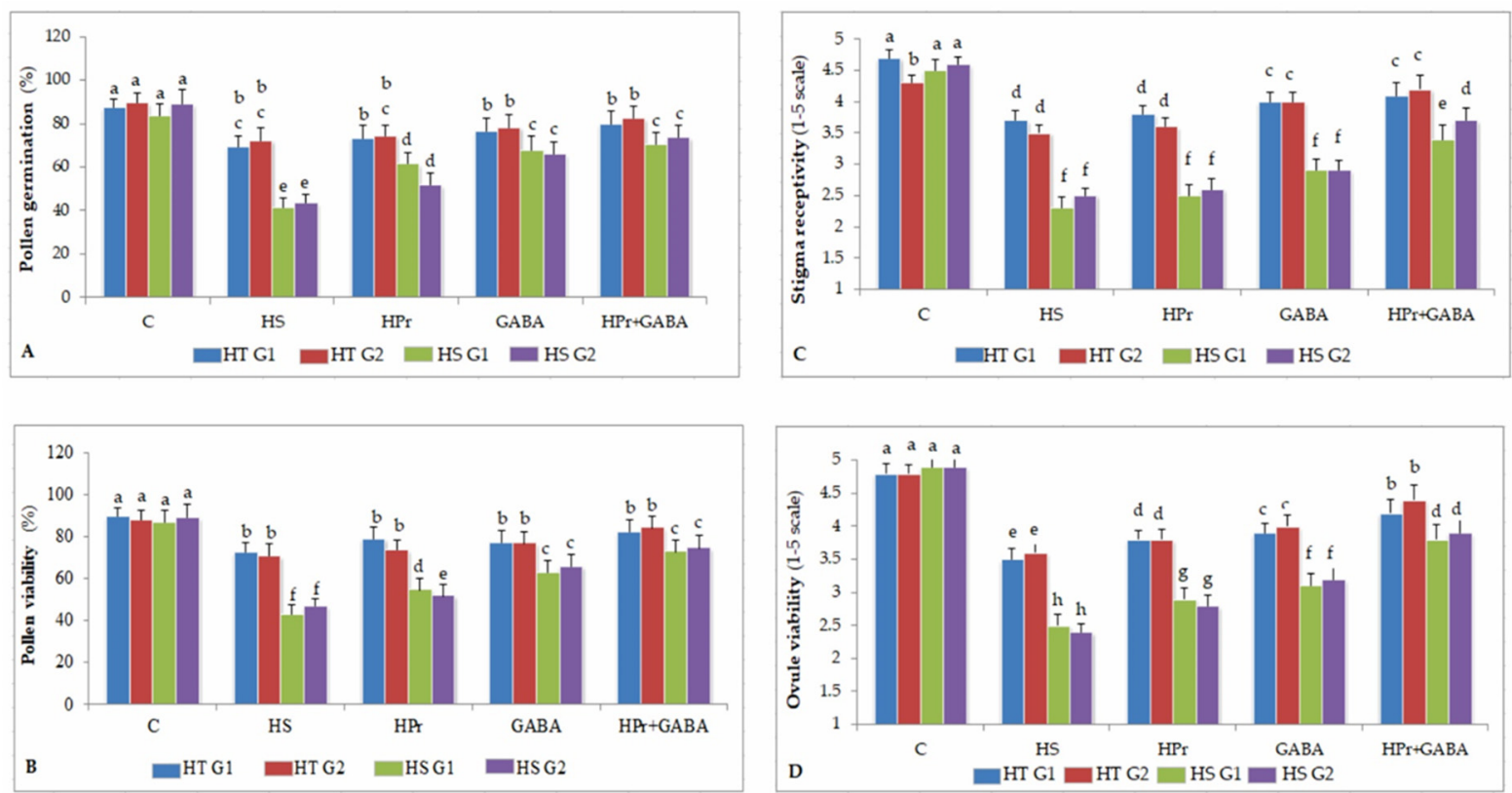

Figure 3. Effect of heat priming ( $\mathrm{HPr}$ ) and $\gamma$-amino butyric acid (GABA), applied individually or in combination $(\mathrm{HPr}+\mathrm{GABA})$ on pollen germination (A), pollen viability (B), stigma receptivity (C) and ovule viability (D) on heattolerant (G1: IG2507; G2: IG3263) and heat-sensitive (G1: IG2821; G2: IG2849) genotypes at stage 1 (S1) and stage 2 (S2) in heat-stressed (HS) lentil plants, compared to control (C). Vertical bars represent standard errors $(n=3)$. Different small letters on the bars indicate significant differences from each other $(p<0.05)$. LSD for interaction (genotypes $\times$ stages $\times$ treatments) $(p<0.05)$ : pollen germination: 6.2 , pollen viability: 6.4 , stigma receptivity: 0.25 , ovule viability: 0.26 .

\subsubsection{Pollen Viability}

Pollen viability (PV; expressed as percentage) in the control plants was $88-89 \%$ in HT and $86-89 \%$ in HS genotypes (Figure 3B). Heat stress reduced PV to $70-72 \%$ in HT and $42-46 \%$ in HS genotypes. The HPr treatment significantly improved PV to $51-54 \%$ in HS genotypes, compared to heat stress alone. Treatment with GABA also increased PV in HS genotypes to $62-66 \%$, with reference to heat stress applied singly. The HPr+GABA treatment markedly improved PV to $81-83 \%$ in HT and $72-74 \%$ in HS genotypes.

\subsubsection{Stigma Receptivity}

Heat stress decreased stigma receptivity (SR) more in HS genotypes (45-49\%) than HT genotypes (19-21\%), compared to the controls (Figure 3C). The GABA treatment alone 
was more effective than the HPr treatment at increasing SR, by $12-26 \%$ in HS and $8-14 \%$ in HT genotypes, compared to heat treatment alone. The HPr+GABA treatment increased SR by $47-48 \%$ in HS genotypes and $11-20 \%$ in HT genotypes, compared with heat stress applied singly.

\subsubsection{Ovule Viability}

Heat stress reduced ovule viability (OV) by $25-27 \%$ in HT and $49-51 \%$ in HS genotypes, in comparison to the controls (Figure 3D). The HPr treatment increased OV by $8 \%$ in HT and $16 \%$ in HS genotypes, and the GABA treatment increased OV by $11 \%$ in $\mathrm{HT}$ and $33 \%$ in HS genotypes, compared to the heat treatment alone. The HPr+GABA treatment improved OV by $20-22 \%$ in HT and $52-62 \%$ in HS genotypes, compared to heat stress alone.

\subsection{Photosynthetic Function}

\subsubsection{Photosynthetic Efficiency}

Photosynthetic efficiency was assessed as chlorophyll fluorescence (ChlF), an indicator of Photosystem II function in the electron transport chain of photosynthesis (Figure 4A). Heat stress, relative to controls, reduced ChlF by $11-13 \%$ during stage 1 and $24-25 \%$ during stage 2 in the HT genotypes and 17-20\% during stage 1 and 32-33\% during stage 2 in the HS genotypes, with respect to the controls. The HPr treatment slightly improved ChlF in the HT and HS genotypes, with reference to heat stress applied singly. The GABA treatment significantly increased $\mathrm{ChlF}$, more so in HS than HT genotypes, compared to heat stress alone. The HPr+GABA treatment increased ChlF by $9-10 \%$ in HT and $8 \%$ in HS genotypes during stage 1 , and $17 \%$ in HT and $19-21 \%$ in HS genotypes during stage 2 , in reference to heat stress applied singly.
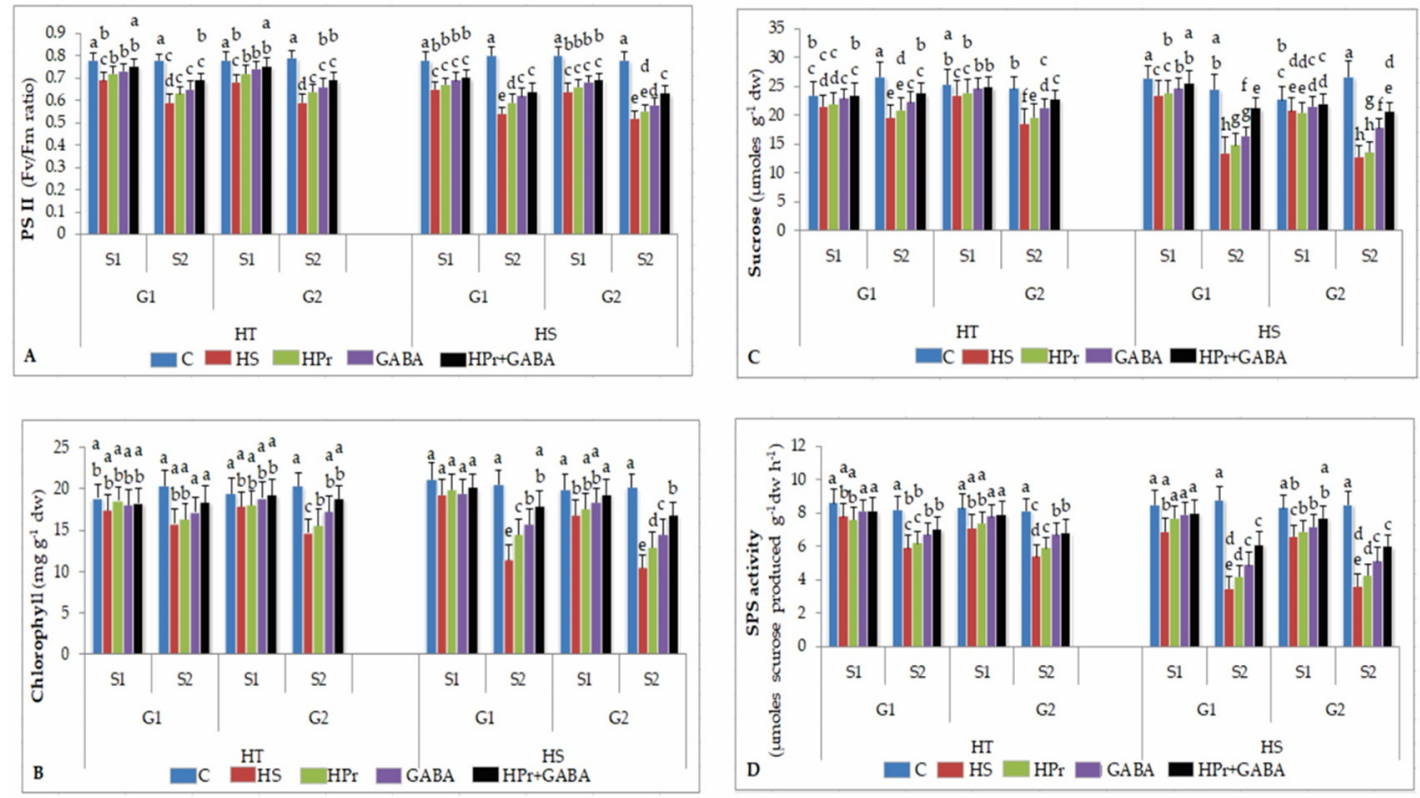

Figure 4. Effect of heat priming (HPr) and $\gamma$-amino butyric acid (GABA), applied individually or in combination (HPr+GABA) on photosystem (PS) II function (A), chlorophyll content (B), sucrose (C) and sucrose phosphate synthase, SPS (D) on heat-tolerant (G1: IG2507; G2: IG3263) and heat-sensitive (G1: IG2821; G2: IG2849) genotypes at stage 1 (S1) and stage 2 (S2) in heat-stressed (HS) lentil plants, compared to control (C). Vertical bars represent standard errors $(n=3)$. Different small letters on the bars indicate significant differences from each other $(p<0.05)$. LSD for interaction (genotypes $\times$ stages $\times$ treatments) $(p<0.05)$ : photosystem II: 0.039 , chlorophyll content: 1.9 ; sucrose: 2.3 , sucrose phosphate synthase: $0.91 . \mathrm{dw}=$ dry weight. 


\subsubsection{Chlorophyll}

Heat stress had little effect on chlorophyll (Chl) concentration in HT genotypes during stage 1, but significantly decreased it in HS genotypes by $9-15 \%$, compared to the control (Figure 4B). During stage 2, heat stress decreased Chl by $44-48 \%$ in HS genotypes and $23-27 \%$ in HT genotypes, with respect to the control. The positive effect of HPr and GABA on improving Chl was more noticeable at stage 2. The HPr treatment increased Chl by $24-27 \%$ in HS genotypes, and the GABA treatment increased Chl by $37-39 \%$ in HS and $9-17 \%$ in HT genotypes, compared to heat stress alone. The HPr+GABA treatment caused more increase, which was $57-61 \%$ in HS and $17-18 \%$ in HT genotypes, with reference to heat stress alone.

\subsubsection{Sucrose}

Heat stress decreased sucrose (Suc) concentration by $8-9 \%$ in HT and $9-11 \%$ in HS genotypes during stage 1 , and by $24-26 \%$ in HT and $45-52 \%$ in HS genotypes during stage 2, in comparison to the controls (Figure 4C). The HPr treatment slightly improved Suc in HT and HS genotypes, more so in HS genotypes, compared to heat stress applied alone. The GABA treatment increased Suc by $14-15 \%$ in HT and $33-39 \%$ in HS genotypes, with reference to heat stress applied singly. The HPr+GABA treatment resulted in more increase in Suc; $37-57 \%$ in HS and $21-23 \%$ in HT genotypes during stage 2, compared to heat stress alone.

\subsubsection{Sucrose Phosphate Synthase}

Heat stress reduced SPS activity by $9-14 \%$ in HT and $18-20 \%$ in HS genotypes during stage 1 and $28-33 \%$ in HT and 59-60\% in HS genotypes during stage 2, with reference to the control (Figure 4D). The HPr treatment increased SPS activity in HS genotypes by $11.5-17 \%$ during stage 1 and $19-20 \%$ during stage 2, compared to heat stress applied singly, but had a smaller effect in HT genotypes. The GABA treatment increased SPS activity in HS genotypes by $9-15 \%$ during stage 1 and $40-41 \%$ during stage 2 , with respect to heat stress alone. For HT genotypes, the GABA treatment had no significant effect on SPS activity during stage 1, but increased it by $13-24 \%$ during stage 2 , in comparison to heat stress applied singly. The HPr+GABA treatment increased SPS activity by $4-11 \%$ in HT and $16-17 \%$ in HS genotypes during stage 1 and $18-26 \%$ in HT and $66-74 \%$ in HS genotypes during stage 2 , compared to heat stress alone.

\subsection{Oxidative Damage}

\subsubsection{Malondialdehyde}

Lipid peroxidation was measured as malondialdehyde (MDA) concentration. Heat stress increased MDA concentrations by $41-42 \%$ in HT and $45-52 \%$ in HS genotypes during stage 1 , with further increases during stage 2, more so in HS genotypes, in comparison to the controls (Figure 5A). The HPr treatment decreased MDA concentrations by $13-20 \%$ in HT and $22 \%$ in HS genotypes during stage 2, with respect to heat stress applied singly. The GABA treatment reduced MDA concentrations by $32-40 \%$ in HT and $33-37 \%$ in HS genotypes during stage 2, compared to heat stress applied singly. On the other hand, the HPr+GABA treatment reduced MDA concentrations by $13-18 \%$ in HT and $18-28 \%$ in HS genotypes during stage 1 and $40-43 \%$ in HT and $51-56 \%$ in HS genotypes during stage 2, with reference to heat stress alone.

\subsubsection{Hydrogen Peroxide}

Heat stress increased $\mathrm{H}_{2} \mathrm{O}_{2}$ concentrations by $56-76 \%$ in $\mathrm{HT}$ and $53-76 \%$ in $\mathrm{HS}$ genotypes during stage 1, which increased further during stage 2, more so in HS genotypes, compared to the controls (Figure 5B). The HPr treatment decreased $\mathrm{H}_{2} \mathrm{O}_{2}$ concentrations by $11-16 \%$ in HT and $7-13 \%$ in HS genotypes during stage 1 and $12-15 \%$ in HT and $17-21 \%$ in HS genotypes during stage 2, in comparison to heat stress applied singly. The GABA treatment reduced $\mathrm{H}_{2} \mathrm{O}_{2}$ concentrations by $22-29 \%$ in $\mathrm{HT}$ and $34-35 \%$ in $\mathrm{HS}$ genotypes 
during stage 2, compared to heat stress alone. The combined treatment ( $\mathrm{HPr}+\mathrm{GABA})$ was more effective in reducing $\mathrm{H}_{2} \mathrm{O}_{2}$ concentrations by $43-47 \%$ in $\mathrm{HT}$ and $51-61 \%$ in $\mathrm{HS}$ genotypes during stage 2 , in comparison to heat stress applied singly.
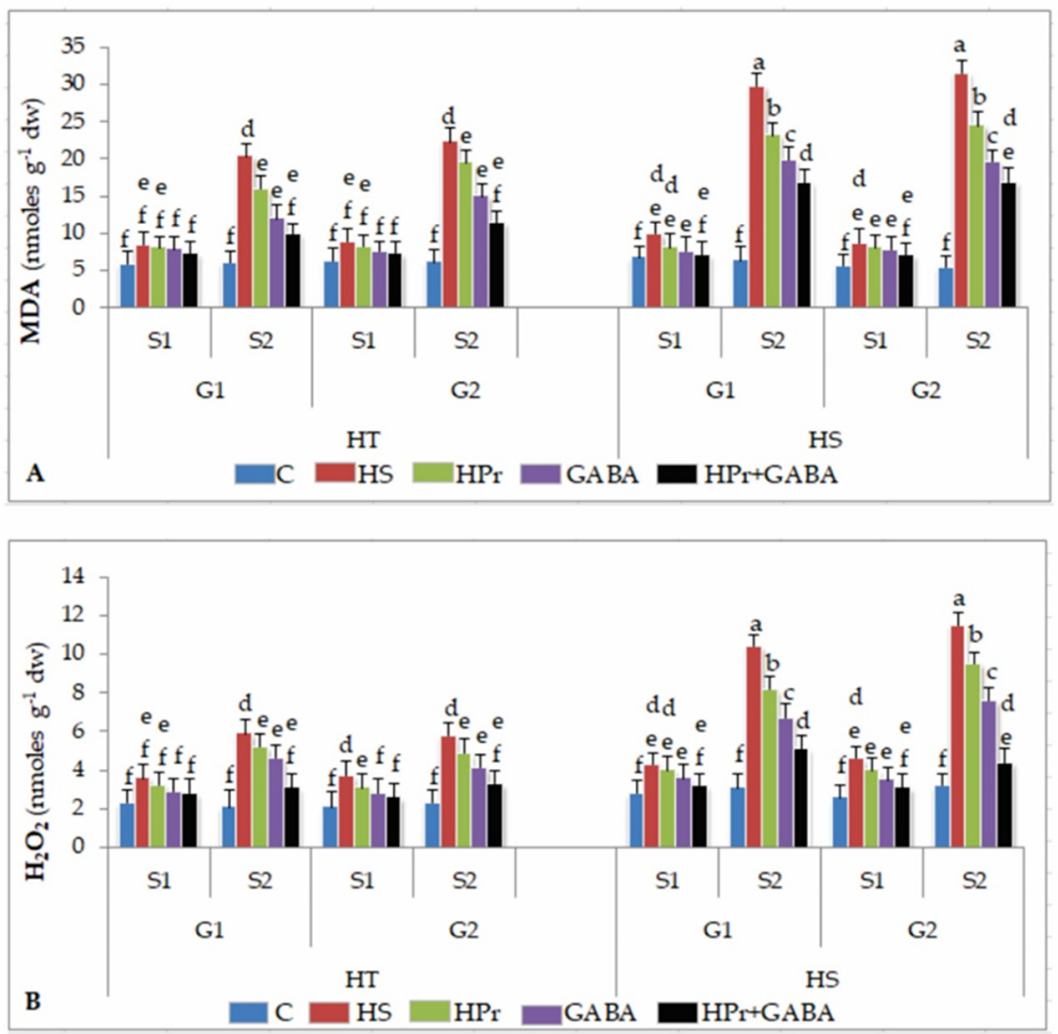

Figure 5. Effect of heat priming (HPr) and $\gamma$-amino butyric acid (GABA), applied individually or in combination ( $\mathrm{HPr}+\mathrm{GABA})$ on malondialdehyde, $\mathrm{MDA}(\mathbf{A})$ and hydrogen peroxide, $\mathrm{H}_{2} \mathrm{O}_{2}(\mathbf{B})$ on heattolerant (G1: IG2507; G2: IG3263) and heat-sensitive (G1: IG2821; G2: IG2849) genotypes at stage 1 (S1) and stage 2 (S2) in heat-stressed (HS) lentil plants, compared to control (C). Vertical bars represent standard errors $(n=3)$. Different small letters on the bars indicate significant differences from each other $(p<0.05)$. LSD for interaction (genotypes $\times$ stages $\times$ treatments $)(p<0.05)$ : malondialdehyde: 1.9 , hydrogen peroxide: $0.74 . \mathrm{dw}=$ dry weight.

\subsection{Antioxidants}

\subsubsection{Superoxide Dismutase (SOD)}

Heat stress increased SOD activity by $12-22 \%$ in HT and $16-22 \%$ in HS genotypes during stage 1, with reference to the controls; during stage 2, SOD activity increased by $29-54 \%$ in HT, but decreased by $33-36 \%$ in HS genotypes, compared to the controls (Figure 6A). The HPr and GABA treatments alone increased SOD activity slightly at both stages, more so with the GABA treatment, with respect to heat stress applied singly. Whereas the HPr+GABA treatment increased SOD activity by $18-24 \%$ in HT and $27-35 \%$ in HS genotypes during stage 1 and $23-32 \%$ in HT and 50-62\% in HS genotypes during stage 2 , in comparison to heat stress alone.

\subsubsection{Catalase (CAT)}

Heat stress increased CAT activity by $27-31 \%$ in HT and 33-37\% in HS genotypes during stage 1, compared to the controls; during stage 2, CAT activity increased by 32-35\% in HT, but decreased by 30-37\% in HS genotypes, compared to the controls (Figure 6B). The HPr and GABA treatments alone significantly increased CAT activity in HS genotypes. The HPr+GABA treatment increased CAT activity by $24-34 \%$ in HT and $26-27 \%$ in HS 
genotypes during stage 1 and $31-33 \%$ in HT and $50-56 \%$ in HS genotypes during stage 2, in comparison to heat stress applied singly.
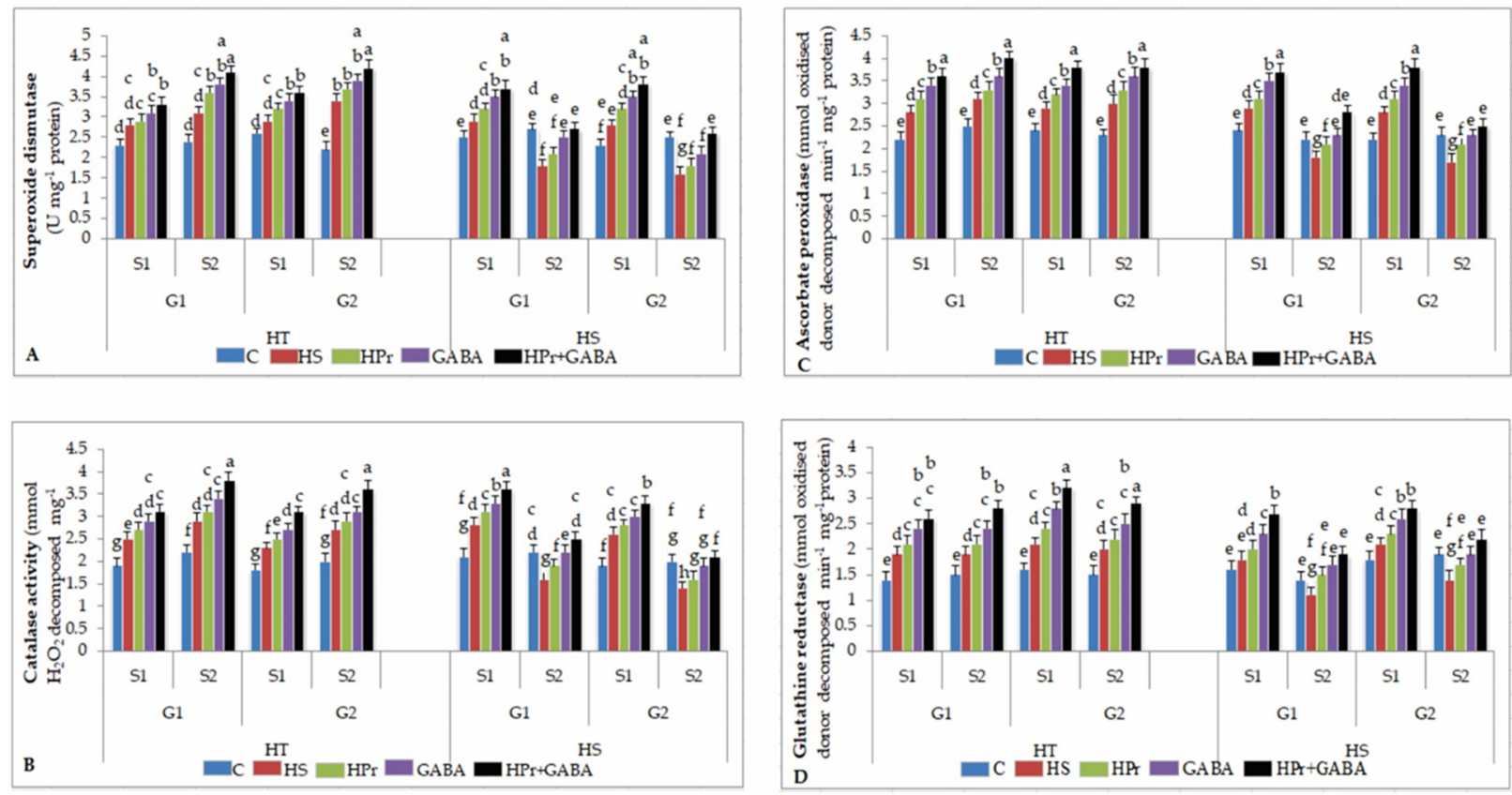

Figure 6. Effect of heat priming (HPr) and $\gamma$-amino butyric acid (GABA), applied individually or in combination $(\mathrm{HPr}+\mathrm{GABA})$ on superoxide dismutase (A), catalase (B), ascorbate peroxidase (C) and glutathione reductase (D) activities on heat-tolerant (G1: IG2507; G2: IG3263) and heat-sensitive (G1: IG2821; G2: IG2849) genotypes at stage 1 (S1) and stage 2 (S2) in heat-stressed (HS) lentil plants, compared to control (C). Vertical bars represent standard errors $(n=3)$. Different small letters on the bars indicate significant differences from each other $(p<0.05)$. LSD for interaction (genotypes $\times$ stages $\times$ treatments) $(p<0.05)$ : superoxide dismutase: 0.21 , catalase: 0.19 ; ascorbate peroxidase: 0.20 , glutathione reductase: 0.19 .

\subsubsection{Ascorbate Peroxidase (APX)}

APX activity increased as a result of heat stress, by $21-27 \%$ and $24-30 \%$ in HT genotypes during stage 1 and stage 2, respectively, compared to the controls; for HS genotypes, APX activity increased by $21-27 \%$ during stage 1 , but decreased by $18-26 \%$ during stage 2 , in relation to the controls (Figure 6C). The HPr treatment increased APX activity by about $10 \%$ in HT and $16-23 \%$ in HS genotypes, with reference to heat stress alone. With GABA treatment, APX activity increased by $17-21 \%$ in HT and $20-21 \%$ in HS genotypes during stage 1 and $14 \%$ in HT and $27-35 \%$ in HS genotypes during stage 2, compared to heat stress applied singly. On the other hand, the HPr+GABA treatment increased APX activity by $21-24 \%$ in $\mathrm{HT}$ and $47-55 \%$ in HS genotypes during stage 2, with reference to heat stress alone.

\subsubsection{Glutathione Reductase (GR)}

Heat stress increased GR activity by $33-35 \%$ in HT and $12-16 \%$ in HS genotypes during stage 1, and $26-33 \%$ in HT and $21-26 \%$ during stage 2, with reference to the controls (Figure 6D). The HPr treatment increased GR activity more in HS than HT genotypes, especially during stage 2 , which increased by $21-36 \%$, compared to heat stress applied singly. The GABA treatment increased GR activity by $25-26 \%$ in HT and $35-54 \%$ in HS genotypes during stage 2, with respect to heat stress alone. The HPr+GABA treatment increased GR activity more in HS (57-72\% increase) than HT genotypes ( $45-47 \%)$, compared to heat stress applied singly. 


\subsection{Osmolytes}

\subsubsection{Proline (Pro)}

Heat stress increased Pro accumulation by $50-56 \%$ in $\mathrm{HT}$ and $42-50 \%$ in HS genotypes during stage 1 , in relation to the controls, with further increases during stage 2 , more so in HT genotypes (Figure 7A). The HPr treatment increased Pro content by $11-16 \%$ in HT and $9-14 \%$ in HS genotypes during stage 1, and $17-22 \%$ in HT and $21-23 \%$ in HS genotypes during stage 2 , with reference to heat stress alone. Pro concentration with GABA treatment increased by $25-27 \%$ in HT and $19-25 \%$ in HS genotypes during stage 1 and $30-32 \%$ in HT and $32-35 \%$ in HS genotypes during stage 2, in comparison to heat stress applied singly. The HPr+GABA treatment further increased Pro accumulation by $42-47 \%$ in HT and $34-40 \%$ in HS genotypes during stage 1 and $51-52 \%$ in HT and $62-65 \%$ in HS genotypes during stage 2 , compared to heat stress alone.
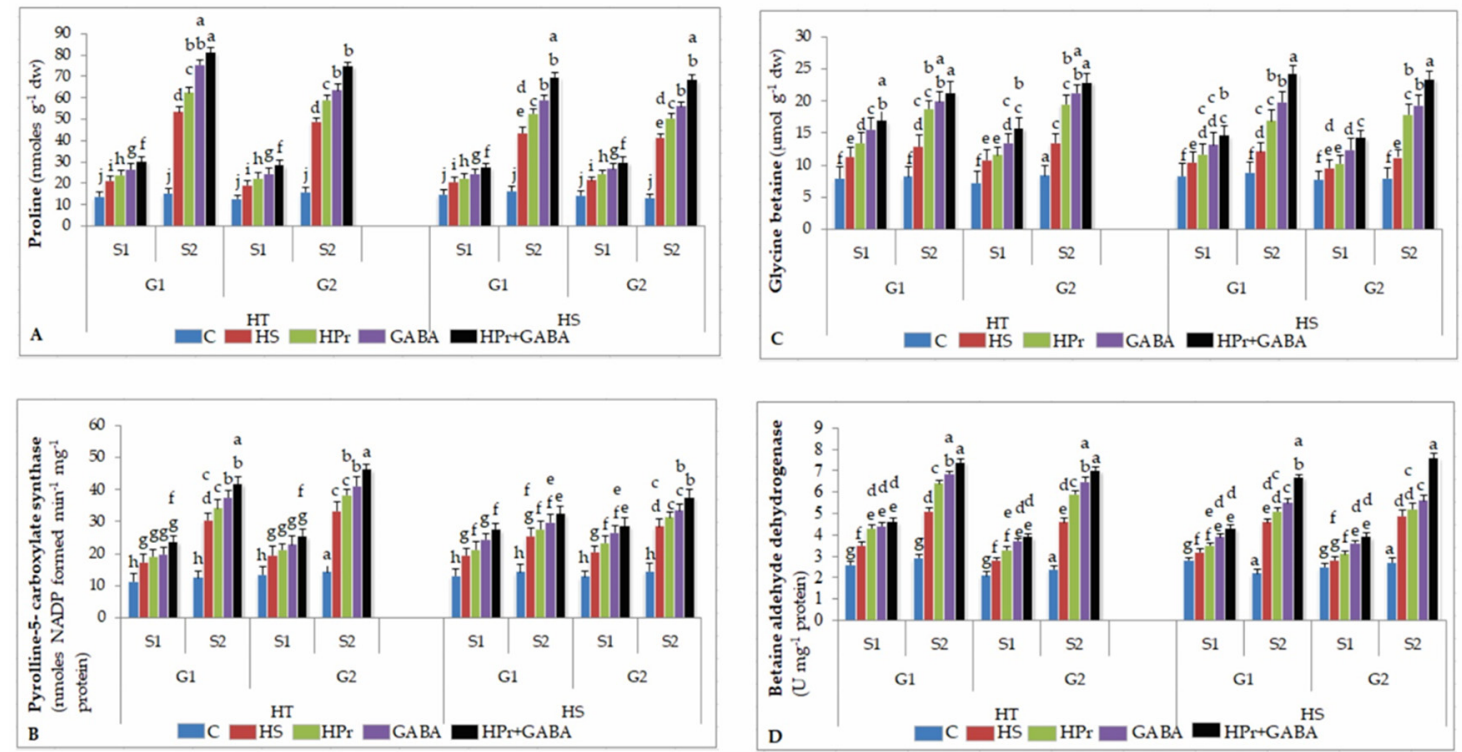

Figure 7. Effect of heat priming ( $\mathrm{HPr}$ ) and $\gamma$-amino butyric acid (GABA), applied individually or in combination (HPr+GABA) on proline (A) and pyrolline-5- carboxylate synthase (B) glycine betaine $(\mathbf{C})$ and betaine aldehyde dehydrogenase (D) on heat-tolerant (G1: IG2507; G2: IG3263) and heat-sensitive (G1: IG2821; G2: IG2849) genotypes at stage 1 (S1) and stage 2 (S2) in heat-stressed (HS) lentil plants, compared to control (C). Vertical bars represent standard errors $(n=3)$. Different small letters on the bars indicate significant differences from each other $(p<0.05)$. LSD for interaction (genotypes $\times$ stages $\times$ treatments) $(p<0.05)$ : proline: 2.7 , pyrolline-5-carboxylate synthase: 2.8 , glycine betaine: 2.8 , betaine aldehyde dehydrogenase: $0.19 . \mathrm{dw}=$ dry weight.

\subsubsection{Pyrroline-5-Carboxylate Synthase (P5CS)}

Heat stress increased P5CS activity by $44-54 \%$ in HT and $46-58 \%$ in HS genotypes during stage 1 and $133-143 \%$ in HT and 77-96\% in HS genotypes during stage 2, with reference to the controls (Figure 7B), which contributed to increase in Pro accumulation. The HPr treatment increased P5CS activity by $20-22 \%$ in HT and $14-17 \%$ in HS genotypes during stage 2, compared to heat stress applied singly. P5CS activity with GABA treatment increased by $33-35 \%$ in HT and $23-26 \%$ in HS genotypes during stage 2, in comparison to heat stress alone. The combination (HPr+GABA) treatment increased P5CS activity by $30-36 \%$ in HT and $29-33 \%$ in HS during stage 1 and $39-43 \%$ in HT and $38-40 \%$ in HS genotypes during stage 2 , with reference to heat stress applied singly.

\subsubsection{Glycine Betaine (GB)}

Heat stress increased GB accumulation by $43-48 \%$ in HT and $24-26 \%$ in HS genotypes during stage 1 and $52-60 \%$ in HT and 36-43\% in HS genotypes during stage 2, with respect to the controls (Figure 7C). GB accumulation with HPr treatment increased by $44-46 \%$ in 
HT and 16-29\% in HS genotypes during stage 2, with reference to heat stress alone. On the other hand, the GABA treatment increased GB accumulation by $54-57 \%$ in HT and $37-40 \%$ in HS genotypes during stage 2, compared to heat stress applied singly. The combined treatment (HPr+GABA) increased GB accumulation by $64-69 \%$ in HT and $74-76 \%$ in HS genotypes during stage 2 , with respect to heat stress applied singly.

\subsubsection{Betaine Aldehyde Dehydrogenase (BADH)}

Heat stress increased BADH activity by 33-34\% in HT and 21-24\% in HS genotypes during stage 1 and 75-91\% in HT and 46-50\% in HS genotypes during stage 2, compared to the controls (Figure 7D). With HPr treatment, the BADH activity increased by $17-18 \%$ in HT and 11-13\% in HS genotypes during stage 1 and $27-28 \%$ in HT and $23-26 \%$ in HS genotypes during stage 2 , in comparison to heat stress alone. The GABA treatment resulted in an increase in BADH activity by $25-32 \%$ in HT and $11-13 \%$ in HS genotypes during stage 1 and $34-42 \%$ in HT and 23-26\% in HS genotypes during stage 2, compared to heat stress applied singly. The combination of HPr+GABA treatment increased BADH activity by $31-37 \%$ in HT and $28-33 \%$ in HS genotypes during stage 1 and $45-53 \%$ in HT and $47-56 \%$ in HS genotypes during stage 2 , in comparison to heat stress alone.

\subsubsection{Endogenous GABA}

Heat stress increased endogenous GABA concentrations by $21-25 \%$ in HT and $13-16 \%$ in HS genotypes during stage 1 whereas at stage 2, HT genotype showed $73-77 \%$ increase in GABA, while a marked reduction (38-40\%) was observed in HS genotype at this stage with respect to the controls (Figure 8). The HPr treatment increased endogenous GABA concentrations by 23 and 30-34\% at stage 1 and 2, respectively, in HT genotypes while in HS genotypes, endogenous GABA concentration showed 12-14\% increase at stage 1 and $48-51 \%$ increase at stage 2 , compared to heat stress applied singly. The exogenous GABA treatment increased the endogenous GABA concentrations, more so in HS genotypes than HT genotypes during both the stages, referring to heat stress alone. The HPr+GABA combination resulted in additional increase in endogenous GABA concentrations in both the genotypes, to a greater extent in HS genotypes, with reference to heat stress alone.

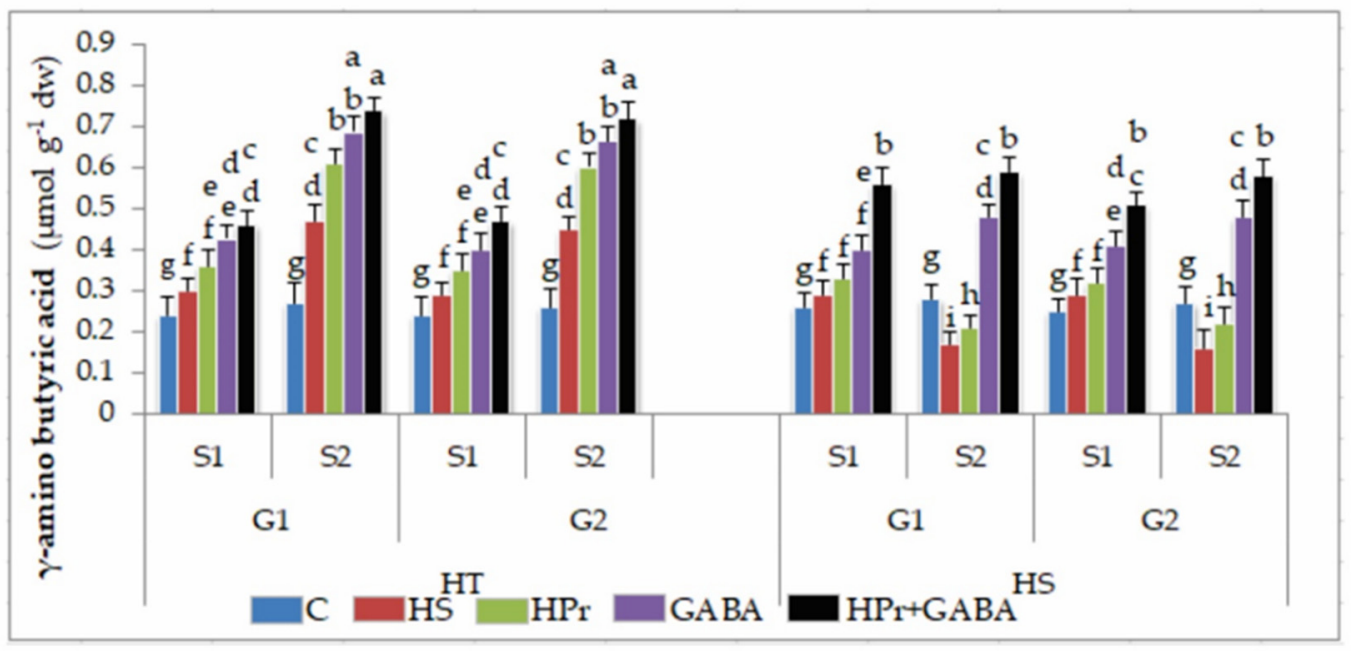

Figure 8. Effect of heat priming ( $\mathrm{HPr}$ ) and $\gamma$-amino butyric acid (GABA), applied individually or in combination (HPr+GABA) on endogenous GABA in heat-tolerant (G1: IG2507; G2: IG3263) and heat-sensitive (G1: IG2821; G2: IG2849) genotypes at stage 1 (S1) and stage 2 (S2) in heat-stressed (HS) lentil plants, compared to control (C). Vertical bars represent standard errors $(n=3)$. Different small letters on the bars indicate significant differences from each other $(p<0.05)$. LSD for interaction (genotypes $\times$ stages $\times$ treatments) $(p<0.05)$ : 0.038. dw $=$ dry weight. 


\subsection{Yield Traits}

\subsubsection{Pod Number}

Heat stress reduced pod number (per plant) more in HS (90\%) than HT $(64-70 \%)$ genotypes, compared to their respective controls (Figure 9A). The HPr treatment had little effect on pod numbers in HT genotypes, but increased it by 13-16\% in HS genotypes, compared to heat stress applied singly. The GABA treatment increased pod numbers by about $10 \%$ in HT and $21-24 \%$ in HS genotypes, in comparison to heat stress alone. The combination of $\mathrm{HPr}+\mathrm{GABA}$ treatment was more effective and increased pod numbers by $21-24 \%$ in HT and $35-38 \%$ in HS genotypes, with respect to heat stress applied singly.
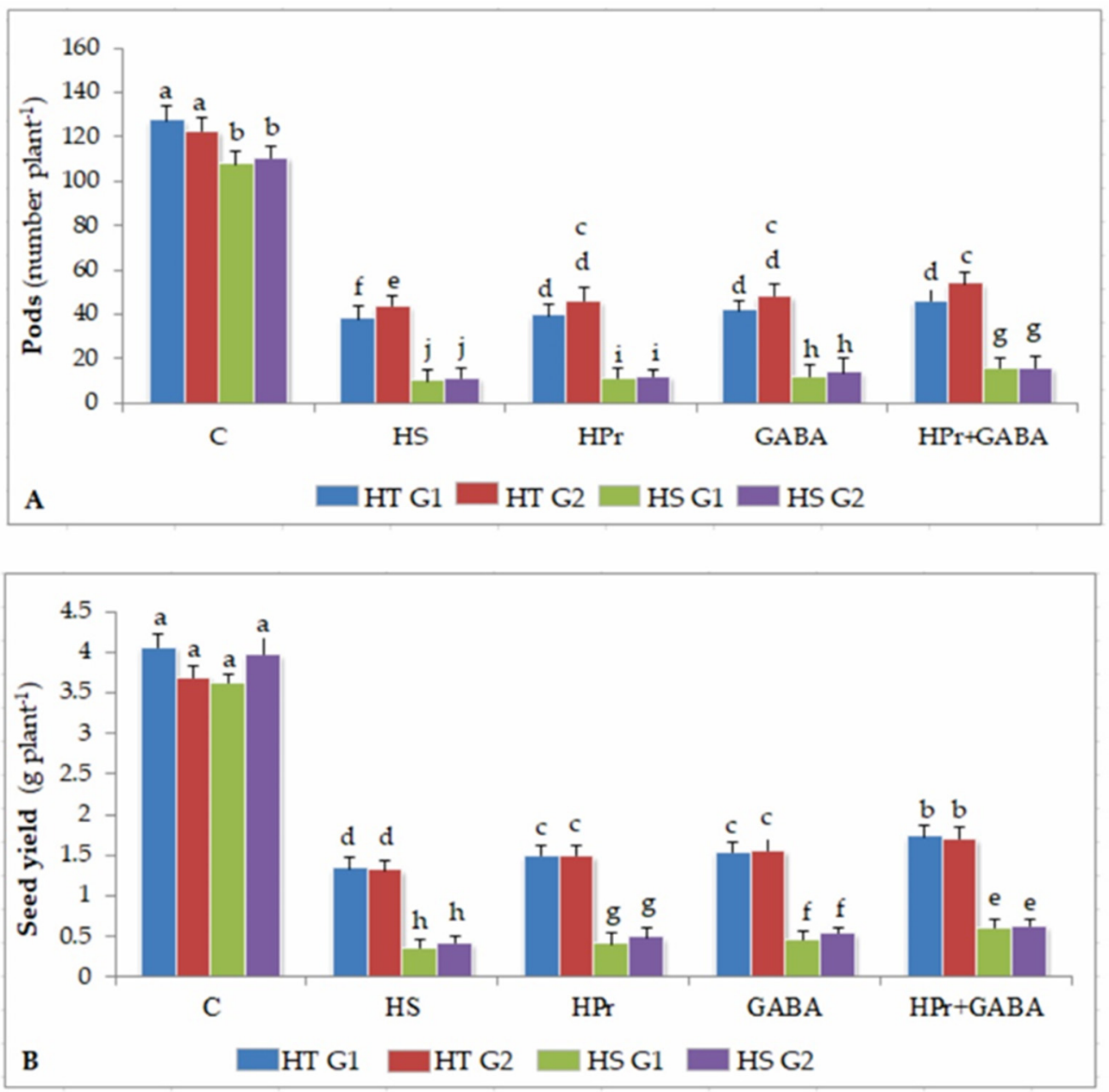

Figure 9. Effect of heat priming (HPr) and $\gamma$-amino butyric acid (GABA), applied individually or in combination (HPr+GABA) on pod number (A) and seed yield/plant (B) in heat-tolerant (HT; G1: IG2507; G2: IG3263) and heat-sensitive (HS; G1: IG2821; G2: IG2849) genotypes in heat-stressed (HS) lentil plants, compared to control (C). Vertical bars represent standard errors $(n=3)$. Different small letters on the bars indicate significant differences from each other $(p<0.05)$. LSD for interaction (genotypes $\times$ stages $\times$ treatments) $(p<0.05)$ : pod number: 6.8 , seed yield/plant: 0.29.

\subsubsection{Seed Yield}

Heat stress decreased seed yield (per plant) by $63-66 \%$ in HT and $90-93 \%$ in HS genotypes, compared to their respective controls. The HPr treatment increased seed yield by $10-13 \%$ in $\mathrm{HT}$ and $14-17 \%$ in HS genotypes, with respect to heat stress alone (Figure $9 \mathrm{~B}$ ). The GABA treatment increased seed yield by $15-18 \%$ in HT and $24-27 \%$ in HS genotypes, compared to heat stress applied singly. The combined HPr+GABA treatment increased seed yield by $22-24 \%$ in HT and $37-40 \%$ in HS genotypes, in comparison to heat stress alone. 


\section{Discussion}

The results of this research showed an opportunity to minimize the impact of heat stress on lentil by heat priming the hydrated seeds (to evoke early defense response through the concept of stress memory), followed by application of GABA. The combination of two treatments significantly enhanced the performance of the heat-stressed lentil plants in terms of reduction in stress injury to leaves (measured on the basis of several indicators) and oxidative damage (as evidenced by significant decrease of MDA and hydrogen peroxidethe 2 key indicators of damage), along with significant upregulation of various enzymatic antioxidants. At the same time, osmolytes (GABA, proline and glycine betaine) showed significant enhancement too due to enhanced activity of their biosynthetic enzymes in heat primed and GABA treated plants. Photosynthetic activity, measured as chlorophyll concentration, PS II function, sucrose, and sucrose synthase enzyme, was noticeably higher in plants grown with primed seeds and GABA treatment. Consequently, the reproductive function (pollen, stigmatic and ovular activity) was significantly more in heat-stressed lentil plants, resulting in considerable improvement in yield traits, such as pod number per plant (21-24\% and $35-38 \%$ in heat tolerant and heat sensitive genotypes, respectively) and seed yield per plant $(22-24 \%$ and $37-40 \%$ in heat tolerant and heat sensitive genotypes, respectively). The present study clearly indicated that various biochemical traits-photosynthetic function, endogenous GABA, proline, glycine betaine and their biosynthetic enzymes, sucrose and its biosynthetic enzyme-were significantly upregulated with combined treatment of heat priming and GABA. There were some positive but weak associations with enhanced yield traits. There might be numerous other mechanisms affecting the yield traits under heat stress, which may need further investigation. These yield responses to treatments may look small, but considering the severe stress conditions and the fact that the plants were grown under controlled environments suggests opportunities. These findings need to be further validated under field conditions using realistic environments and under different stress levels with a greater number of genotypes.

\subsection{Impacts of Heat Stress}

Heat stress impacted the lentil plants at various levels of organization, as noticed in the present study. Loss of membrane integrity because of heat stress can be attributable to disruption of lipid-protein interactions in membranes [24] and is similar to our previous studies on heat-stressed chickpea [25] and lentil [7] plants. The reductions in leaf water status possibly occurred because of decrease in stomatal conductance and hydraulic conductivity [26] and match the earlier observations in heat-stressed lentil [7]. Damage to mitochondrial integrity and denaturation or inhibition of respiratory enzymes [6] might have resulted in decrease in cellular oxidizing ability in heat-stressed lentil plants, which agrees with the observations on heat-stressed plants of cotton [27], wheat [28], chickpea [25] and potato (Solanum tuberosum L.) [29].

Heat stress resulted in significant reduction in chlorophyll (Chl) causing chlorosis at stage 2, more so in heat-sensitive genotypes, which was likely because of inhibition in chlorophyll biosynthesis or increase in its degradation of chlorophyll and/or disorganization of chloroplasts because of photooxidation [30]. Similar observations have been reported in plants of chickpea (Cicer arietinum L.) [25], tomato (Solanum lycopersicum L.) [31], and mungbean (Vigna radiata L.) [5] subjected to heat stress. Inhibition of PSII (photosystem II) function because of heat stress indicates disrupted electron transport and the denaturation of the oxygen-evolving enzymes of PSII light reactions of photosynthesis. PS II function has been used as a vital measure of thermotolerance [32]. Consequently, photosynthetic ability was inhibited, which was also associated with decrease in activity of sucrose-synthesizing enzyme (sucrose-P-synthase; SPS), resulting in impaired sucrose production in the present study, which agrees with previous findings in heat-stressed chickpea [33]. The disruption of pollen function (germination and viability), stigma and ovular activity, more so in heat-sensitive than heat-tolerant genotypes, confirmed our previous findings in heat-stressed lentil [7]. Diminished sucrose levels in the leaves of heat-stressed 
lentil plants and its transport might have inhibited the reproductive function [7] resulting in poor pod number.

The osmolytes such as Pro, GB, and GABA showed significant increase in their concentration because of heat stress, pertinently in HT genotypes, while a marked reduction in their endogenous concentration was noticed in HS genotypes, as the stress progressed. Osmolytes tend to maintain homeostasis and perform diverse defense-related functions in the stressed cells [34-36], thus, poor levels of these osmolytes could be one of the reasons contributing to greater sensitivity of HS genotypes to heat stress. The reduction in Pro and GB concentration in HS genotypes correlated with inhibition of their biosynthesizing enzymes (P5CS and BADH, respectively).

The oxidative molecules, such as Malondialdehyde (MDA) and hydrogen peroxide $\left(\mathrm{H}_{2} \mathrm{O}_{2}\right)$, increased markedly in heat-stressed plants, and more in heat-sensitive genotypes. The increase in oxidative molecules might have caused membrane damage, chlorosis, necrosis, and loss of mitochondrial and chloroplast integrity in our study, which is similar to findings in heat-stressed wheat [37], chickpea [38], and lentil [39]. Cells control their redox status by up-regulating various enzymatic and non-enzymatic antioxidants [40]. Heat stress reduced the expression of these antioxidants, particularly at stage 2, more in heat-sensitive than heat-tolerant lentil genotypes, resulting in higher levels of oxidative molecules. Heat stress can impair the antioxidative mechanism by denaturing enzymes and reducing substrate availability [41], thus causing damage to various cellular components and tissues.

These adverse effects of heat stress resulted in reduction in yield traits (number of pods, seeds), which were more severe in heat-sensitive genotypes because of greater damage to reproductive and cellular function, as described above.

\subsection{Effect of Treatments}

Due to heat stress, endogenous GABA concentration showed a marked reduction in HS genotypes as the stress progressed, while HT genotypes retained high GABA levels. GABA has been reported to improve leaf photosynthesis, stabilize membranes, and upregulate antioxidants and osmoprotectants in stressed cells [17,42]. Thus, diminution of endogenous GABA concentration in HS genotypes, under heat stress, might have been a critical factor increasing the damage to leaf tissues and reproductive function [43]. In the present study, we investigated the involvement of GABA in deciding the heat sensitivity. Hence, we explored whether heat priming the lentil seeds and foliar GABA application, alone or in combination, could increase the endogenous GABA concentration and thus improve the performance of heat-stressed lentil plants. Results indicated that HPr and GABA treatments considerably increased the endogenous GABA concentration, and effectively protected lentil plants from heat injury, especially when applied in combination (HPr+GABA). While the exogenous GABA treatment might have directly complemented its endogenous concentration, the increase because of heat priming might have occurred because of enhanced expression of enzyme glutamate decarboxylase, involved in GABA synthesis, as noticed in cold-acclimated wheat and barley (Hordeum vulgare L.) plants [44], which needs to be probed further. Here, we heat primed the hydrated seeds, instead of the plants (as done previously in some studies), to test the efficacy of this treatment on subsequent heat tolerance as well as to increase the practical utility of this technique, which proved to be effective in enhancing the heat stress tolerance in lentil plants. These findings are in consonance with some earlier studies reporting the beneficial effects of heat priming treatment (by subjecting the plants at the vegetative stage to moderately high temperature) on subsequent high temperature tolerance in Arabidopsis [13] and wheat [12]. Heat priming the seeds may induce 'stress memory' since the plants have evolved suitable mechanisms to remember the previous stress events and can react to subsequent stress events more quickly and strongly. These mechanisms include epigenetic changes, transcriptional priming, changes in proteins' confirmation and metabolic and hormonal 'signatures' [45]. 
The combination of HPr and exogenous GABA was more effective in this regard and resulted in significantly improved leaf water status and stomatal conductance, particularly during stage 2. This might possibly be related to the facilitation of osmolytes' accumulation, such as proline and GB, attributable to improved activity of their biosynthetic enzymes. Thus preventing damage to membranes and cellular oxidizing ability in the leaves. Osmolytes, besides contributing to turgor generation, have several other protective roles in stressed cells [46]. As a result, the leaves of plants treated with HPr+GABA combination showed less damage to chlorophyll thus preventing injury to photosynthetic activity (as PS II function). Mitigation of damage to leaves by this combined treatment might also be ascribed to reduced oxidative stress, associated with enhanced expression of antioxidants, as noticed in heat-stressed rice [17], salt-stressed maize (Zea mays L.) [19], and cold-stressed peach [47]. Our observations also match a previous study where heat-acclimated wheat plants showed less disruption in PSII function in a heat-stressed environment [48]. The $\mathrm{HPr}+\mathrm{GABA}$ treatment contributed to stabilization of photosynthetic function causing optimization of sucrose production, as indicated by activity of sucrose synthesizing enzyme and sucrose concentration, which is considered critical to sustain vegetative and reproductive growth [33]. In a previous study in Arabidopsis, heat priming the plants was found to increase sucrose accumulation [13], which was associated with enhanced thermotolerance. Thus, the reproductive function in heat-stressed lentil plants was significantly improved by combined treatments, possibly because of enhanced sucrose availability to flowers and their components, which might have minimized the impact of heat stress to pollen function, resulting in an improved pod set [25]. The direct involvement of GABA in maintaining pollen fertility has been indicated earlier [23], which supports our observations. Thus, the present study showed that HPr and GABA treatments, especially when applied together, improved the pod number and seed yield of lentil plants under heat-stress.

\section{Materials and Methods}

\subsection{Plant Growth Conditions, Treatments, Phenology and Yield Traits}

\subsubsection{Plant Growth Conditions}

Seeds of four lentil genotypes (two heat-tolerant (IG2507, IG3263), two heat-sensitive (IG2821, IG2849)), procured from the Indian Institute of Pulses Research, Kanpur, Uttar Pradesh, India; phenology (Figure 1), were heat primed at $35^{\circ} \mathrm{C}$ for $6 \mathrm{~h}$ in the dark in Petridishes having double-layered filter paper moistened with distilled water (slow hydration) in a growth chamber maintained at $35^{\circ} \mathrm{C}$ and relative humidity of $90 \%$ in the dark. A preliminary experiment tested the priming time $(2,4,6$, and $8 \mathrm{~h})$ and temperatures $(30,32$, and $35^{\circ} \mathrm{C}$ ), and determined $6 \mathrm{~h}$ at $35^{\circ} \mathrm{C}$ to be appropriate for improving the performance of plants at $32 / 20^{\circ} \mathrm{C}$. For 'control' and 'heat-stress alone' treatments, the seeds were put in the dark in Petri-dishes with double-layered filter papers, moistened with distilled water for $6 \mathrm{~h}$ in a controlled environment at $28 / 18^{\circ} \mathrm{C}$ (day/night). The seeds were sown directly after priming, as a preliminary study revealed that drying the seeds to original moisture reduced the effectiveness of the treatment. The primed seeds were sown in pots $(10 \mathrm{~cm}$ diameter; $7 \mathrm{~kg}$ capacity) filled with a sandy loam soil (sand: silt: clay in $63.4 \%, 24.6 \%$ and $12 \%$ ) mixed with sand in a 3:1 ratio. Rhizobium spp., specific to lentil, was added to the soil prior to sowing. Soil used in the present study had a mixture (3:1) of soil-sand and part farmyard manure, $10 \mathrm{mg} \mathrm{kg}^{-1}$ of tricalcium phosphate [38]. The plants were raised in October at Panjab University, Chandigarh, India in a natural environment (see Figure 10 for temperature data) until the onset of flowering (105-107 days after sowing depending on the genotype). The average temperature was $25 / 15^{\circ} \mathrm{C}$ (day/night), light intensity ranged from $1350-1550 \mu \mathrm{mol} \mathrm{m}^{-2} \mathrm{~s}^{-1}$ and mean relative humidity $(\mathrm{RH})$ values ranged from $62-69 \%$. 


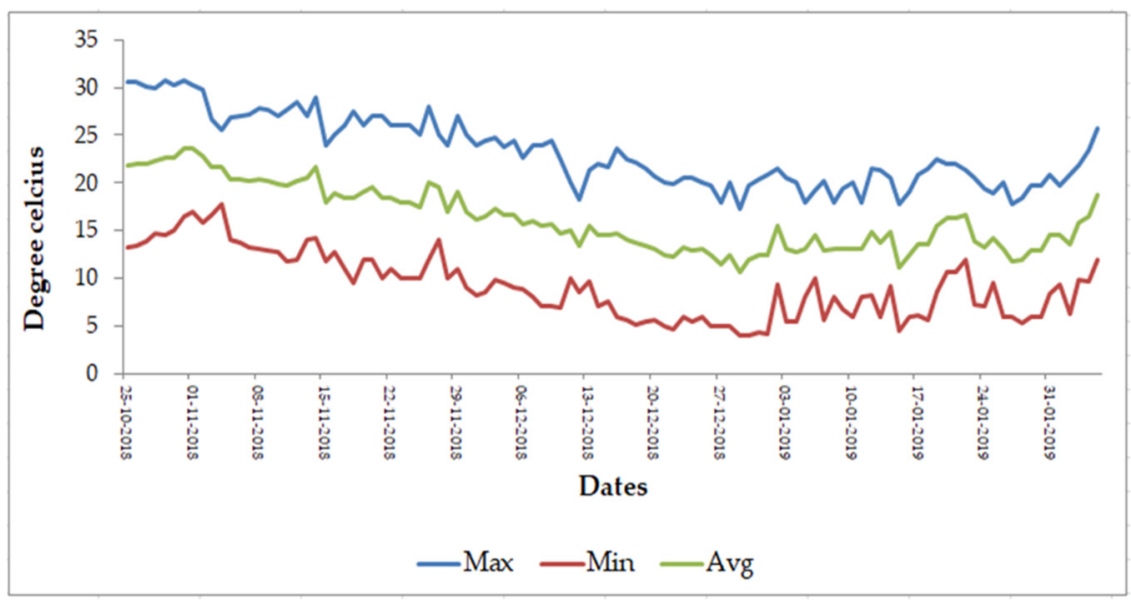

Figure 10. Temperature profile (maximum (Max), minimum (Min) and average (Avg)) from sowing to onset of flowering in outdoor environment at the experimental site.

\subsubsection{Treatments}

At the onset of flowering, one set (half) of plants was maintained in a controlled environment at $28 / 18{ }^{\circ} \mathrm{C}$ (day/night, $12 \mathrm{~h}$ each), light intensity of $500 \mu \mathrm{mol} \mathrm{m}^{-2} \mathrm{~s}^{-1}$, and $\mathrm{RH}$ of $65-70 \%$, while the other set was subjected to heat stress $\left(32 / 20^{\circ} \mathrm{C}\right.$, day $/$ night; $12 \mathrm{~h}$ each) up to maturity, with similar light and $\mathrm{RH}$ values to the control. For the heat-stress treatment, the plants were kept initially at $28 / 18^{\circ} \mathrm{C}$ for one day, before gradually increasing the temperature by $2{ }^{\circ} \mathrm{C} /$ day to achieve the desired temperature $\left(32 / 20^{\circ} \mathrm{C}\right.$; day /night; $12 \mathrm{~h}$ each). The plants were treated with a foliar application of GABA $(1 \mathrm{mM})$, along with Tween 20 (as a surfactant), one day before final exposure to heat stress $\left(32 / 20^{\circ} \mathrm{C}\right.$; day/night; $12 \mathrm{~h}$ each), and again five days later.

The treatments were as follows:

1. Control;

2. Heat-stress alone;

3. Heat-primed seeds + Heat-stress;

4. Heat-stress + GABA $(1 \mathrm{mM})$ as a foliar treatment;

5. Heat-primed seeds + Heat-stress + GABA $(1 \mathrm{mM})$ as a foliar treatment.

The plants were assessed for various leaf traits at stage 1 (6th day of exposure to $32 / 20^{\circ} \mathrm{C}$ ) and stage $2\left(15\right.$ th day of exposure to $32 / 20^{\circ} \mathrm{C}$ ). Phenology was recorded during different growth stages, while yield traits were examined at maturity.

\subsubsection{Phenology and Yield Traits}

Phenology observations (number of days taken to show flowering, podding, maturity, flowering-podding interval, podding-maturity interval; Figure 1) were recorded on five plants per genotype in each replicate (15 plants per genotype), pooled and averaged. Mature seeds were harvested for recording yield data, the seeds were dried at $45^{\circ} \mathrm{C}$ in hot air oven for three days; these were weighed, and the average values were recorded on the basis of per plant [33].

\subsection{Stress Injury}

\subsubsection{Membrane Damage (as Electrolyte Leakage)}

Fresh leaves (100 mg) (young, 2-3rd node from the top; for all the traits examined) beneath to the flowers were collected at both stages to measure electrolyte leakage [49]. Leaf segments were cleaned with water (deionized), kept in glass vials (capped) with ten $\mathrm{mL}$ deionized water at $25^{\circ} \mathrm{C}$ for $12 \mathrm{~h}$. The electrical conductivity (C1) of the surrounding solution was recorded after $24 \mathrm{~h}$. Subsequently, leaf segments were placed for 10-15 min in a water bath (maintained at $80^{\circ} \mathrm{C}$ ). The final reading of electrical conductivity reading (C2) 
was recorded upon equilibration [25]. The values for electrolyte leakage were measured using the equation $\mathrm{C} 1 / \mathrm{C} 2 \times 100$ and expressed as percentage.

\subsubsection{Relative Leaf Water Content}

Relative leaf water content (RLWC) was measured to assess the leaf water status [50]. Leaves subtending flowers $(100 \mathrm{mg}$; fresh weight $(\mathrm{FW}))$ were collected, floated in a Petri dish having distilled water for $2 \mathrm{~h}$, thereafter, these were taken out, and dried of their surface with filter paper; these were weighed again (turgid weight, TW) before oven-drying for $24 \mathrm{~h}$ at $110^{\circ} \mathrm{C}$; these were weighed again for dry weight (DW). It was calculated as $(\mathrm{FW}-\mathrm{DW}) /(\mathrm{TW}-\mathrm{DW}) \times 100$; expressed as percentage.

\subsubsection{Stomatal Conductance}

Stomatal conductance (gs) of leaves beneath the flowers was measured with a portable leaf porometer (Decagon Devices, Pullman, Washington, USA) was used to measure [25], and expressed as $\mathrm{mmol}^{-1} \mathrm{~s}^{-1}$.

\subsubsection{Cellular Oxidizing Ability}

Cellular oxidizing ability was assessed using TTC (2, 3, 5-triphenyl tetrazolium chloride) reduction ability. Fresh leaf samples (100 $\mathrm{mg}$ ) were excised into small segments and dipped in incubation solution containing sodium phosphate (pH 7.4; $50 \mathrm{mM})$, TTC (500 mg $100 \mathrm{~mL}^{-1}$ solution) [51]. The leaf samples were placed in dark at $25^{\circ} \mathrm{C}$ for one hour without shaking as TTC reduction is responsive to excessive oxygen. After extracting twice with $5 \mathrm{~mL}$ of $95 \%$ ethanol, the extracts were pooled to make final volume of $10 \mathrm{~mL}$. The color developed due to production of Formazan was read with a Spectrophotometer at $530 \mathrm{~nm}$, rather than $485 \mathrm{~nm}$, to minimize any interference by pigments like chlorophyll [25]. The readings are given as absorbance/g fresh weight.

\subsection{Reproductive Function}

\subsubsection{Pollen Germination}

The germination of pollen grains was tested in a growth medium with potassium nitrate ( $990 \mathrm{mM}$; $\mathrm{pH}$ 6.5), calcium nitrate $(1269 \mathrm{mM})$, magnesium sulfate $(812 \mathrm{mM})$, sucrose $(10 \%)$, and boric acid $(1640 \mathrm{mM})[25,52]$. Pollen grains were recorded as germinated when the pollen tube size increased more than the pollen grain's diameter. The germination was measured from about hundred pollen grains per replicate.

\subsubsection{Pollen Viability}

Pollen viability was tested using $0.5 \%$ acetocarmine, involving about 200 pollen grains in 5 microscopic fields [25]. The collection of the pollen grains was done from flowers on day of anthesis, and the pollen grains were combined and examined for their viability [53]. The traits used for measuring pollen viability were size and shape (triangular or spherical) and the color intensity of the pollen grains. Dense color indicated higher pollen viability [25], expressed as percentage.

\subsubsection{Stigma Receptivity}

Stigma receptivity was examined by esterase test following the method of [54]. A day prior to opening of flower, stigmas were harvested from the flowers. These were placed at $37^{\circ} \mathrm{C}$ for $15 \mathrm{~min}$ in a solution with $\alpha$-NAA and fast blue B prepared in phosphate buffer. The stigmas develop colors of varying intensity depending upon their receptivity and are rated on 1-5 scale (5-high receptivity, 1-low receptivity) [25].

\subsubsection{Ovule Viability}

For testing ovule viability, the ovules were harvested from the ovary of flowers one day before anthesis, which were kept on a slide containing few drops of TTC solution ( $0.5 \%$ TTC in $1 \%$ sucrose solution), covered with a cover slip, and placed in a Petri-dish 
containing double layered moistened filter paper. These were incubated at $25^{\circ} \mathrm{C}$ in the dark for $15 \mathrm{~min}$ in a chamber. The ovules were tested for viability on the basis of red color intensity of the stain, particularly in the center. The color intensity depends upon the respiring ability of the ovules and is rated on 1-5 scale (5-highest intensity, 1-lowest intensity) [25].

\subsection{Leaf Photosynthetic Function}

\subsubsection{Photochemical Efficiency}

For this purpose, chlorophyll fluorescence (as $\mathrm{Fv} / \mathrm{Fm}$ ratio) was measured from the young leaves, close to flowers, using chlorophyll fluorometer OS1-FL (Opti-Sciences, Hudson, NH, USA) [25].

\subsubsection{Chlorophyll}

For extracting chlorophyll, fresh leaves $(500 \mathrm{mg}$ ) were extracted using $80 \%$ acetone, and the extract was centrifuged at $5702 \times g$. The supernatant was collected, and its absorbance was read in a spectrophotometer at 645 and $663 \mathrm{~nm}$ [55], expressed as $\mathrm{mg} \mathrm{g}^{-1}$ dry weight.

\subsubsection{Sucrose}

For measuring sucrose concentration, extraction of fresh leaves (500 $\mathrm{mg}$ ) was done in $80 \%$ ethanol for $1.5 \mathrm{~h}$ at $80{ }^{\circ} \mathrm{C}$ two times, followed by pooling of these extracts. These were evaporated in oven (air-circulating) at $40^{\circ} \mathrm{C}$ and tested for sucrose concentration [56], as detailed previously [25], expressed as $\mu$ moles $\mathrm{g}^{-1}$ dry weight.

\subsubsection{Sucrose Phosphate Synthase}

Fresh leaves (beneath the flowers) were collected and extracted in a chilled $50 \mathrm{mM}$ HEPES buffer- $\mathrm{NaOH}$ (pH 7) with $\mathrm{MgCl}_{2}$ (2 mM), EDTA (1 mM), and DTT (2 mM) [57]. Sephadex G-25 columns, kept at $4{ }^{\circ} \mathrm{C}$, were used for desalting of the supernatant. Prior to this, these columns were pre-equilibrated using a buffer having HEPES-NaOH ( $\mathrm{pH}$ 7.5; $20 \mathrm{mM}), \mathrm{MgCl}_{2}(0.25 \mathrm{mM}), 2$-mercaptoethanol $(0.01 \%)$, ethylenediaminetetraacetic acid (EDTA; $1 \mathrm{mM})$, and BSA $(0.05 \%)$. To assay the enzyme activity, from this extract, anthrone test was used [58], as detailed previously [7]. The activity was expressed as $\mu$ moles sucrose produced $\mathrm{g}^{-1}$ dry weight $\mathrm{h}^{-1}$.

\subsection{Soluble Proteins}

Oven-dried leaves were homogenized in $0.1 \mathrm{M}$ phosphate buffer ( $\mathrm{pH} 7.0)$, followed by centrifugation at $514 \mathrm{~g}$ for $15 \mathrm{~min}$ [7]. The concentration of soluble proteins was quantified following the method of [59]. These were expressed as $\mathrm{mg} \mathrm{g}^{-1}$ dry weight.

\subsection{Osmolytes and Related Enzymes}

\subsubsection{Proline and Pyrroline-5-Carboxylate Synthase}

For measuring proline, the leaf tissue was extracted using $3 \%$ sulphosalicylic acid, and it was centrifuged $20 \mathrm{~min}$ at $4{ }^{\circ} \mathrm{C}$ at $2150 \mathrm{~g}$. The supernatant was treated with acidic ninhydrin reagent and read at $520 \mathrm{~nm}$; toluene was used a blank [60]. The concentration was expressed as nmoles $\mathrm{g}^{-1}$ dry weight.

To measure pyrroline-5-carboxylate synthase (P5CS) activity, tissue samples were homogenized in potassium phosphate buffer $(0.1 \mathrm{M} ; \mathrm{pH} 7.5)$ with mercaptoethanol (10 mM), EDTA $(1 \mathrm{mM})$, polyvinylpyrrolidone $\left(1 \%(\mathrm{~m} / \mathrm{v}), \mathrm{KCl}(0.6 \mathrm{M}), \mathrm{MgCl}_{2}(5 \mathrm{mM})\right.$ in a precooled pestle and mortar. The extract was centrifuged at $3360 \mathrm{~g}$ for $30 \mathrm{~min}$ at $4{ }^{\circ} \mathrm{C}$ in a cold centrifuge. The desalting of the enzyme extract was done in Sepahdex columns at $4{ }^{\circ} \mathrm{C}$; the enzyme activity was measured [61] and expressed as nmoles NADP formed $\min ^{-1} \mathrm{mg}^{-1}$ protein. 


\subsubsection{Glycine Betaine and Betaine Aldehyde Dehydrogenase}

Leaf tissue was dried in an oven and crushed to make fine powder, before adding twenty $\mathrm{ml}$ of deionized water, and shaking at $25^{\circ} \mathrm{C}$ for $24 \mathrm{~h}$. Using $2 \mathrm{~N} \mathrm{H}_{2} \mathrm{SO}_{4}$, the extracts were diluted (1:1) and measured for glycine betaine concentration [62]. The concentration was expressed as $\mu$ moles $\mathrm{g}^{-1}$ dry weight.

Briefly, the activity of the enzyme betaine aldehyde dehydrogenase (BADH) was assayed as follows. The leaf tissue was extracted in a medium with HEPES-KOH buffer ( $\mathrm{pH} 8.0 ; 50 \mathrm{mM})$, EDTA $(1 \mathrm{mM})$, dithiothreitol $(5 \mathrm{mM})$, ascorbic acid $(5 \mathrm{mM})$, sodium borate $(10 \mathrm{mM})$, sodium metabisulfite $(20 \mathrm{mM})$, and PVP [ $2 \%(w / v)]$. The extract was centrifuged at $4{ }^{\circ} \mathrm{C}$ for $15 \mathrm{~min}$ at $3360 \times \mathrm{g}$. After desalting the enzyme extract, the activity was measured at $340 \mathrm{~nm}$ [63]. The activity was expressed as $\mathrm{U} \mathrm{mg}^{-1}$ protein,

\subsubsection{Endogenous GABA}

Leaf tissue was extracted in $8 \%(\mathrm{~m} / \mathrm{v})$ trichloroacetic acid (TCA) at $3360 \times \mathrm{g}$ for $1 \mathrm{~min}$ at $25^{\circ} \mathrm{C}$, and then centrifuged for $20 \mathrm{~min}$ at $3360 \times \mathrm{g}$. The supernatant was collected, followed by addition of $4 \mathrm{~mL}$ pure diethyl ether, mixing briskly for $10 \mathrm{~min}$, and centrifuging for $20 \mathrm{~min}$ at $3360 \times \mathrm{g}$. The supernatant after collection was allowed to stand in the open air for evaporation of ether for $30 \mathrm{~min}$ and tested for GABA concentration [64], which was expressed as $\mu$ moles $\mathrm{g}^{-1}$ dry weight.

\subsection{Oxidative Molecules and Antioxidants}

\subsubsection{Malondialdehyde}

For, malondialdehyde (MDA), fresh leaf tissue was extracted in trichloroacetic acid (TCA; $0.1 \%$ ), followed by centrifugation for $5 \mathrm{~min}$ at $3360 \times \mathrm{g}$. The reaction was carried out by mixing $0.1 \mathrm{~mL}$ of supernatant with thiobarbituric acid $(4 \mathrm{~mL} ; 0.5 \%)$, prepared in TCA $(20 \%)$. The contents were heated for $0.5 \mathrm{~h}$ at $95^{\circ} \mathrm{C}$, which were subsequently cooled in an ice bath. It was centrifuged at $3360 \times g$ for $10 \mathrm{~min}$ at $4{ }^{\circ} \mathrm{C}$, followed by recording its absorbance at $532 \mathrm{~nm}$. The extinction coefficient of $155 \mathrm{mM}^{-1} \mathrm{~cm}^{-1}$ was used for calculating the concentration of MDA [65], which was expressed as nmoles $\mathrm{g}^{-1}$ dry weight.

\subsubsection{Hydrogen Peroxide}

Fresh plant tissue was extracted in $5 \mathrm{~mL}$ chilled acetone (80\%), the extract was filtered using a Whatman filter paper. The filtrate was reacted with titanium reagent $(4 \mathrm{~mL})$, followed by addition of ammonia solution $(25 \%, 5 \mathrm{~mL})$. It was centrifuged at $3360 \mathrm{~g}$; the supernatant was discarded, followed by dissolution of the residue $1 \mathrm{M} \mathrm{H}_{2} \mathrm{SO}_{4}$. The optical density of the resultant solution was read at $410 \mathrm{~nm}$. The $\mathrm{H}_{2} \mathrm{O}_{2}$ concentration was measured with the help of the extinction coefficient of $\mathrm{H}_{2} \mathrm{O}_{2}\left(0.28 \mathrm{mmol}^{-1} \mathrm{~cm}^{-1}\right)$ [66] and expressed as expressed as nmoles $\mathrm{g}^{-1}$ dry weight.

\subsubsection{Superoxide Dismutase}

For assaying superoxide dismutase (SOD; E.C. 1.15.1.1) activity from fresh leaf tissue, the extraction was done in a pre-cooled phosphate buffer ( $50 \mathrm{mM}$; $\mathrm{pH} 7.0)$, followed by centrifugation ( $3360 \mathrm{~g}$ ) $4{ }^{\circ} \mathrm{C}$ for $5 \mathrm{~min}$. The supernatant was tested for enzyme activity. The reaction mixture comprised of phosphate buffer $(\mathrm{pH} 7.8 ; 50 \mathrm{mM})$, enzyme extract $(0.1 \mathrm{~mL})$, sodium bicarbonate $(50 \mathrm{mM})$, nitro blue tetrazolium chloride (NBT; $25 \mathrm{mM})$, methionine $(13 \mathrm{mM})$, EDTA $(0.1 \mathrm{mM})$ in an entire volume of three $\mathrm{mL}$. Subsequently, after addition of riboflavin $(2 \mathrm{mM})$, the reaction mixture was exposed for $10 \mathrm{~min}$ to a $15 \mathrm{~W}$ fluorescent light. The absorbance was taken at $560 \mathrm{~nm}$. The enzyme activity was measured using the method of Dhindsa and Matowe [67], which was expressed as Units $\mathrm{mg}^{-1}$ protein.

\subsubsection{Catalase}

The activity of Catalase (CAT; E.C. 1.11.1.6) was assayed as per Teranishi et al. [68]. The enzyme extract prepared for assaying the SOD activity was also used for CAT activity. To the reaction mixture ((enzyme extract $(0.1 \mathrm{~mL})$ and phosphate buffer $(\mathrm{pH} 7.0 ; 50 \mathrm{mM}))$, 
$\mathrm{H}_{2} \mathrm{O}_{2}(200 \mathrm{mM})$ was included to start the reaction. The optical density (at $410 \mathrm{~nm}$ ) was read for $3 \mathrm{~min}$. The activity of enzyme was determined by means of extinction coefficient of $40 \mathrm{mM}^{-1} \mathrm{~cm}^{-1}$ and expressed as $\mathrm{mmol}_{2} \mathrm{O}_{2}$ decomposed $\mathrm{mg}^{-1}$ protein.

\subsubsection{Ascorbate Peroxidase}

The reaction mixture $(3 \mathrm{~mL})$ comprised of enzyme extract, which was prepared for SOD, phosphate buffer (pH 7.0; $50 \mathrm{mM})$, EDTA $(0.1 \mathrm{mM})$ and ascorbic acid (ASC; $0.5 \mathrm{mM}$ ). Subsequently, hydrogen peroxide (as a substrate) was added to the reaction mixture. Ascorbate peroxidase (APX; E.C. 1.11.1.11) activity was measured as the decline in absorbance at $290 \mathrm{~nm}$ by recording the oxidation of ascrobate and calculated using the extinction coefficient of $2.8 \mathrm{mM}^{-1} \mathrm{~cm}^{-1}$ [69]. The activity was expressed as mmol oxidized donor decomposed $\mathrm{min}^{-1} \mathrm{mg}^{-1}$ protein.

\subsubsection{Glutathione Reductase}

For assaying glutathione reductase (GR; E.C. 1.6.4.2), the reaction mixture had phosphate buffer $(1.5 \mathrm{~mL} ; 100 \mathrm{mM}, \mathrm{pH} 7.6)$, BSA $(0.20 \mathrm{~mL})$, NADP $(0.35 \mathrm{~mL})$, glutathione oxidized (GSSG; $0.1 \mathrm{~mL}$ ), and enzyme extract $(0.1 \mathrm{~mL}$; as above for SOD). The activity was assayed as decline in absorbance for $3 \mathrm{~min}$ at $340 \mathrm{~nm}$ [70] and expressed as mmol oxidized donor decomposed $\mathrm{min}^{-1} \mathrm{mg}^{-1}$ protein.

\subsection{Statistical Analysis}

The experiment had four contrasting genotypes (two heat-tolerant and two heatsensitive) and four treatments. Each treatment was comprised of eight pots per genotype (two plants per pot) in triplicate (24 pots per treatment; 48 plants per treatment). Three pots in triplicate (nine plants per treatment; 18 plants per genotype) were maintained separately for yield trait measurements. The pots were kept following a randomized block design in controlled environment. All the traits were analyzed in 3 replicates. Analysis of variance (ANOVA) for genotypes $\times$ treatment $\times$ stages interaction was conducted using Agristat software, and the least significant values (LSD) values were calculated $(p<0.05)$. Tukey's post hoc test was used to compare means.

\section{Conclusions}

The present study revealed that HPr and exogenous application of GABA increased the endogenous GABA concentration, along with several other defense-related mechanisms to reduce the heat stress injury to the leaves and reproductive function resulting in improved yield-related traits. Thus, maintaining an appropriate endogenous GABA concentration might be a vital mechanism associated with heat tolerance in lentil at reproductive stages. The findings showed for the first time that combining heat priming of the hydrated seeds with foliar GABA treatment provides an opportunity to reducing the effects of heat stress in lentil. Further research is needed to validate these studies under field conditions, find a more practical and simple method of heat priming, determine the economics of cost and return on investment associated with heat priming and GABA application under field conditions.

Author Contributions: Conceptualization, H.N., K.H.M.S., and U.J.; methodology, A.B., K.S., A.S., and K.B.; formal analysis, H.N. and U.J.; resources, S.K. and J.K.; writing-original draft preparation, H.N.; writing, review and editing, H.N. and P.V.V.P.; supervision, H.N.; project administration, H.N.; funding acquisition, H.N. and P.V.V.P. All authors have read and agreed to the published version of the manuscript.

Funding: This research received no external grant funding beyond support from the Panjab University.

Institutional Review Board Statement: Not applicable.

Informed Consent Statement: Not applicable.

Data Availability Statement: Data available upon request from corresponding author. 
Acknowledgments: H.N. is thankful to the Department of Science and Technology, Department of Biotechnology, Department of Science and Technology Purse Award from the Ministry of Agriculture, India; Consultative Group of International Agricultural Research, International Center for Agricultural Research in the Dryland Area (ICARDA-Morocco); and The University of Western Australia for funding the infrastructural facilities. K.S. and A.B. are thankful to Council of Scientific and Industrial Research, India; and ICARDA, Morocco, for providing the fellowships during study. Contribution No. 21-307-J from Kansas Agricultural Experiment Station.

Conflicts of Interest: The authors declare no conflict of interest.

\section{References}

1. Siebert, S.; Ewert, F. Future crop production threatened by extreme heat. Environ. Res. Lett. 2014, 9, 1-4. [CrossRef]

2. Prasad, P.V.V.; Bheemanahalli, R.; Jagadish, S.K. Field crops and the fear of heat stress-opportunities, challenges and future directions. Field Crops Res. 2017, 200, 114-121. [CrossRef]

3. Kaushal, N.; Bhandari, K.; Siddique, K.H.; Nayyar, H. Food crops face rising temperatures: An overview of responses, adaptive mechanisms, and approaches to improve heat tolerance. Cogent Food Agric. 2016, 2, 1-42. [CrossRef]

4. Zinn, K.E.; Tunc-Ozdemir, M.; Harper, J.F. Temperature stress and plant sexual reproduction: Uncovering the weakest links. J. Exp. Bot. 2010, 61, 1959-1968. [CrossRef]

5. Kaur, R.; Bains, T.S.; Bindumadhava, H.; Nayyar, H. Responses of mungbean (Vigna radiata L.) genotypes to heat stress: Effects on reproductive biology, leaf function and yield traits. Sci. Hortic. 2015, 197, 527-541. [CrossRef]

6. Sita, K.; Sehgal, A.; HanumanthaRao, B.; Nair, R.M.; Prasad, P.V.V.; Kumar, S.; Nayyar, H. Food legumes and rising temperatures: Effects, adaptive functional mechanisms specific to reproductive growth stage and strategies to improve heat tolerance. Front. Plant Sci. 2017, 8, 1-30. [CrossRef] [PubMed]

7. Sita, K.; Sehgal, A.; Kumar, J.; Kumar, S.; Singh, S.; Siddique, K.H.M.; Nayyar, H. Identification of high-temperature tolerant lentil (Lens culinaris Medik.) genotypes through leaf and pollen traits. Front. Plant Sci. 2017, 8, 744. [CrossRef]

8. Roy, C.D.; Tarafdar, S.; Das, M.; Kundagrami, S. Screening lentil (Lens culinaris Medik.). Trends Biosci. 2012, 5, $143-146$.

9. Roy, S.; Islam, M.A.; Sarker, A.; Ismail, M.R.; Rafii, M.Y.; Mondal, M.M.A.; Malek, M.A. Morphological characterization of lentil accessions: Qualitative characters. Bangladesh J. Bot. 2012, 41, 187-190. [CrossRef]

10. Delahunty, A.; Nuttall, J.; Nicolas, M.; Brand, J. Genotypic heat tolerance in lentil. In Proceedings of the 17th ASA Conference, Hobart, Australia, 20-24 September 2015.

11. Mendanha, T.; Rosenqvist, E.; Hyldgaard, B.; Ottosen, C.O. Heat priming effects on anthesis heat stress in wheat cultivars (Triticum aestivum L.) with contrasting tolerance to heat stress. Plant Physiol. Biochem. 2018, 132, 213-221. [CrossRef]

12. Fan, Y.; Ma, C.; Huang, Z.; Abid, M.; Jiang, S.; Dai, T.; Han, X. Heat priming during early reproductive stages enhances thermotolerance to post-anthesis heat stress via improving photosynthesis and plant productivity in winter wheat (Triticum aestivum L.). Front. Plant Sci. 2018, 9, 805. [CrossRef] [PubMed]

13. Serrano, N.; Ling, Y.; Bahieldin, A.; Mahfouz, M.M. Thermopriming reprograms metabolic homeostasis to confer heat tolerance. Sci. Rep. 2019, 9, 1-14. [CrossRef] [PubMed]

14. Sharma, L.; Priya, M.; Kaushal, N.; Bhandhari, K.; Chaudhary, S.; Dhankher, O.P.; Nayyar, H. Plant growth-regulating molecules as thermoprotectants: Functional relevance and prospects for improving heat tolerance in food crops. J. Exp. Bot. 2020, 71, 569-594. [CrossRef]

15. Ramesh, S.A.; Tyerman, S.D.; Gilliham, M.; Xu, B. $\gamma$-Aminobutyric acid (GABA) signaling in plants. Cell Mole. Life Sci. 2017, 74, 1577-1603. [CrossRef] [PubMed]

16. Ramos-Ruiz, R.; Martinez, F.; Knauf-Beiter, G. The effects of GABA in plants. Cogent Food Agric. 2019, 5, 1670553. [CrossRef]

17. Nayyar, H.; Kaur, R.; Kaur, S.; Singh, R. $\gamma$-Aminobutyric acid (GABA) imparts partial protection from heat stress injury to rice seedlings by improving leaf turgor and upregulating osmoprotectants and antioxidants. J. Plant Growth Regul. 2014, 33, 408-419. [CrossRef]

18. Li, Z.; Peng, Y.; Huang, B. Physiological effects of $\gamma$-aminobutyric acid application on improving heat and drought tolerance in creeping bentgrass. J. Am. Soc. Hortic. Sci. 2016, 141, 76-84. [CrossRef]

19. Wang, Y.; Gu, W.; Meng, Y.; Xie, T.; Li, L.; Li, J.; Wei, S. $\gamma$-Aminobutyric acid imparts partial protection from salt stress injury to maize seedlings by improving photosynthesis and upregulating osmoprotectants and antioxidants. Sci. Rep. 2017, 7, 43609. [CrossRef]

20. Kinnersley, A.M.; Lin, F. Receptor modifiers indicate that 4-aminobutyric acid (GABA) is a potential modulator of ion transport in plants. Plant Growth Regul. 2000, 32, 65-76. [CrossRef]

21. Bouche, N.; Fromm, H. GABA in plants: Just a metabolite? Trends Plant Sci. 2004, 9, 110-115. [CrossRef]

22. Locy, R.D.; Wu, S.J.; Bisnette, J.; Barger, T.W.; McNabb, D.; Zik, M.; Cherry, J.H. The regulation of GABA accumulation by heat stress in Arabidopsis. In Plant Tolerance to Abiotic Stresses in Agriculture: Role of Genetic Engineering; Springer: Dordrecht, The Netherlands, 2000; Volume 83, pp. 39-52.

23. Biancucci, M.; Mattioli, R.; Forlani, G.; Funck, D.; Costantino, P.; Trovato, M. Role of proline and GABA in sexual reproduction of angiosperms. Front. Plant Sci. 2015, 6, 680. [CrossRef] [PubMed] 
24. Hofmann, N.R. The plasma membrane as first responder to heat stress. Plant Cell 2009, 21, 2544. [CrossRef]

25. Kaushal, N.; Awasthi, R.; Gupta, K.; Gaur, P.; Siddique, K.H.; Nayyar, H. Heat-stress-induced reproductive failures in chickpea (Cicer arietinum) are associated with impaired sucrose metabolism in leaves and anthers. Funct. Plant Biol. 2013, 40, 1334-1349. [CrossRef]

26. Morales, D.; Rodríguez, P.; Dell'Amico, J.; Nicolas, E.; Torrecillas, A.; Sánchez-Blanco, M.J. High-temperature preconditioning and thermal shock imposition affects water relations, gas exchange and root hydraulic conductivity in tomato. Biol. Plant 2003 47, 203. [CrossRef]

27. Jaconis, S.Y.; Thompson, A.; Smith, S.L.; Trimarchi, C.; Cottee, N.S.; Bange, M.P.; Conaty, W.C. A standardised approach for determining heat tolerance in cotton using triphenyl tetrazolium chloride. Sci. Rep. 2021, 11, 5419. [CrossRef]

28. Ibrahim, M.H.A.; Quick, J.S. Heritability of heat tolerance in winter and spring wheat. Crop. Sci. 2001, 41, 1401-1405. [CrossRef]

29. Coria, N.A.; Sarquís, J.I.; Peñalosa, I.; Urzúa, M. Heat-induced damage in potato (Solanum tuberosum) tubers: Membrane stability, tissue viability, and accumulation of glycoalkaloids. J. Agric. Food Chem. 1998, 46, 4524-4528. [CrossRef]

30. Tewari, A.K.; Tripathy, B.C. Temperature-stress-induced impairment of chlorophyll biosynthetic reactions in cucumber and wheat. Plant Physiol. 1998, 117, 851-858. [CrossRef] [PubMed]

31. Camejo, D.; Rodríguez, P.; Morales, M.A.; Dell'Amico, J.M.; Torrecillas, A.; Alarcón, J.J. High temperature effects on photosynthetic activity of two tomato cultivars with different heat susceptibility. J. Plant Physiol. 2005, 162, 281-289. [CrossRef]

32. Vander Westhuizen, M.M.; Oosterhuis, D.M.; Berner, J.M.; Boogaers, N. Chlorophyll a fluorescence as an indicator of heat stress in cotton (Gossypium hirsutum L.). S. Afr. J. Plant Soil. 2020, 37, 116-119. [CrossRef]

33. Awasthi, R.; Kaushal, N.; Vadez, V.; Turner, N.C.; Berger, J.; Siddique, K.H.; Nayyar, H. Individual and combined effects of transient drought and heat stress on carbon assimilation and seed filling in chickpea. Funct. Plant Biol. 2014, 41, 1148-1167. [CrossRef] [PubMed]

34. Liang, X.; Zhang, L.; Natarajan, S.K.; Becker, D.F. Proline mechanisms of stress survival. Antioxid. Redox Signal. 2013, $19,998-1011$. [CrossRef] [PubMed]

35. Giri, J. Glycine betaine and abiotic stress tolerance in plants. Plant Signal. Behav. 2011, 6, 1746-1751. [CrossRef]

36. Fernandez, O.; Béthencourt, L.; Quero, A.; Sangwan, R.S.; Clément, C. Trehalose and plant stress responses: Friend or foe? Trends Plant Sci. 2010, 15, 409-417. [CrossRef]

37. Fábián, A.; Sáfrán, E.; Szabó-Eitel, G.; Barnabás, B.; Jäger, K. Stigma functionality and fertility are reduced by heat and drought co-stress in wheat. Front. Plant Sci. 2019, 10, 244. [CrossRef] [PubMed]

38. Awasthi, R.; Gaur, P.; Turner, N.C.; Vadez, V.; Siddique, K.H.; Nayyar, H. Effects of individual and combined heat and drought stress during seed filling on the oxidative metabolism and yield of chickpea (Cicer arietinum) genotypes differing in heat and drought tolerance. Crop. Pasture Sci. 2017, 68, 823-841. [CrossRef]

39. Chakraborty, U.; Pradhan, D. High temperature-induced oxidative stress in Lens culinaris, role of antioxidants and amelioration of stress by chemical pre-treatments. J. Plant Interact. 2011, 6, 43-52. [CrossRef]

40. Awasthi, R.; Bhandari, K.; Nayyar, H. Temperature stress and redox homeostasis in agricultural crops. Front. Environ. Sci. 2015, 3, 11. [CrossRef]

41. Suzuki, N.; Mittler, R. Reactive oxygen species and temperature stresses: A delicate balance between signaling and destruction. Physiol Plant. 2006, 126, 45-51. [CrossRef]

42. Wang, Y.; Luo, Z.; Mao, L.; Ying, T. Contribution of polyamines metabolism and GABA shunt to chilling tolerance induced by nitric oxide in cold-stored banana fruit. Food Chem. 2016, 197, 333-339. [CrossRef]

43. Priya, M.; Sharma, L.; Kaur, R.; Bindumadhava, H.; Nair, R.M.; Siddique, K.H.M.; Nayyar, H. GABA ( $\gamma$-aminobutyric acid), as a thermo-protectant, to improve the reproductive function of heat-stressed mungbean plants. Sci. Rep. 2019, 9, 1-14. [CrossRef]

44. Mazzucotelli, E.; Tartari, A.; Cattivelli, L.; Forlani, G. Metabolism of $\gamma$-aminobutyric acid during cold acclimation and freezing and its relationship to frost tolerance in barley and wheat. J. Exp. Bot. 2006, 57, 3755-3766. [CrossRef]

45. Hilker, M.; Schmulling, T. Stress priming, memory, and signalling in plants. Plant Cell Environ. 2019, 42, 743-761. [CrossRef]

46. Oukarroum, A.; El Madidi, S.; Strasser, R.J. Exogenous glycine betaine and proline play a protective role in heat-stressed barley leaves (Hordeum vulgare L.): A chlorophyll a fluorescence study. Plant Biosyst. 2012, 146, 1037-1043. [CrossRef]

47. Yang, A.; Cao, S.; Yang, Z.; Cai, Y.; Zheng, Y. $\gamma$-Aminobutyric acid treatment reduces chilling injury and activates the defence response of peach fruit. Food Chem. 2011, 129, 1619-1622. [CrossRef]

48. Végh, B.; Marček, T.; Karsai, I.; Janda, T.; Darkó, É. Heat acclimation of photosynthesis in wheat genotypes of different origin. S. Afr. J. Plant Soil. 2018, 117, 184-192. [CrossRef]

49. Lutts, S.; Kinet, J.M.; Bouharmont, J. NaCl-induced senescence in leaves of rice (Oryza sativa L.) cultivars differing in salinity resistance. Ann. Bot. 1996, 78, 389-398. [CrossRef]

50. Barrs, H.D.; Weatherley, P.E. A re-examination of the relative turgidity technique for estimating water deficit in leaves. Aust. J. Biol. Sci. 1962, 15, 413-428. [CrossRef]

51. Steponkus, P.L.; Lanphear, F.O. Refinement of the triphenyl tetrazolium chloride method of determining cold injury. Plant Physiol. 1967, 42, 1423-1426. [CrossRef]

52. Brewbaker, J.L.; Kwack, B.H. The essential role of calcium ion in pollen germination and pollen tube growth. Am. J. Bot. 1963, 50, 859-865. [CrossRef]

53. Alexander, M.P. Differential staining of aborted and non-aborted pollen. Stain Technol. 1969, 44, 117-122. [CrossRef] [PubMed] 
54. Mattison, O.; Knox, R.B.; Heslop-Harrison, J.; Heslop-Harrison, Y. Protein pellicle of stigmatic papillae as a probable recognition site in incompatible reactions. Nature 1974, 247, 298-300. [CrossRef]

55. Arnon, D.I. Copper enzymes in isolated chloroplast. Plant Physiol. 1949, 24, 1-15. [CrossRef]

56. Jones, M.G.; Outlaw, W.H.; Lowry, O.H. Enzymic assay of 10-7 to 10-14 moles of sucrose in plant tissues. Plant Physiol. 1997, 60, 379-383. [CrossRef]

57. Déjardin, A.; Rochat, C.; Maugenest, S.; Boutin, J.P. Purification, characterization and physiological role of sucrose synthase in the pea seed coat (Pisum sativum L.). Planta 1997, 201, 128-137. [CrossRef]

58. Huber, J.L.; Huber, S.C.; Nielsen, T.H. Protein phosphorylation as a mechanism for regulation of spinach leaf sucrose-phosphate synthase activity. Arch. Biochem. Biophys. 1989, 270, 681-690. [CrossRef]

59. Lowry, O.H.; Rosebrough, N.J.; Farr, A.L.; Randall, R.J. Measurement of protein with the Folin phenol reagent. J. Biol. Chem. 1951, 193, 265-275. [CrossRef]

60. Bates, L.S.; Waldren, R.P.; Teare, I.D. Rapid determination of free proline for water-stress studies. Plant Soil 1973, 39, 205-207. [CrossRef]

61. Filippou, P.; Bouchagier, P.; Skotti, E.; Fotopoulos, V. Proline and reactive oxygen/nitrogen species metabolism is involved in the tolerant response of the invasive plant species Ailanthus altissima to drought and salinity. Environ. Exp. Bot. 2014, 97, 1-10. [CrossRef]

62. Grieve, C.M.; Grattan, S.R. Rapid assay for determination of water soluble quaternary ammonium compounds. Plant Soil 1983, 70, 303-307. [CrossRef]

63. Daniell, H.; Muthukumar, B.; Lee, S.B. Marker free transgenic plants: Engineering the chloroplast genome without the use of antibiotic selection. Curr. Genet. 2001, 39, 109-116. [CrossRef]

64. Saito, T.; Matsukura, C.; Sugiyama, M.; Watahiki, A.; Ohshima, I.; Iijima, Y.; Nishimura, S. Screening for $\gamma$-aminobutyric acid (GABA)-rich tomato varieties. J. Jpn. Soc. Hortic. Sci. 2008, 77, 242-250. [CrossRef]

65. Heath, R.L.; Packer, L. Photoperoxidation in isolated chloroplasts: I. Kinetics and stoichiometry of fatty acid peroxidation. Arch. Biochem. Biophys. 1968, 125, 189-198. [CrossRef]

66. Mukherjee, S.P.; Choudhuri, M.A. Implications of water stress-induced changes in the levels of endogenous ascorbic acid and hydrogen peroxide in Vigna seedlings. Physiol. Plant 1983, 58, 166-170. [CrossRef]

67. Dhindsa, R.S.; Matowe, W. Drought tolerance in two mosses: Correlated with enzymatic defence against lipid peroxidation. J. Exp. Bot. 1981, 32, 79-91. [CrossRef]

68. Teranishi, Y.; Tanaka, A.; Osumi, M.; Fukui, S. Catalase activities of hydrocarbon-utilizing Candida yeasts. Agric. Biol. Chem. 1974, 38, 1213-1220. [CrossRef]

69. Nakano, Y.; Asada, K. Hydrogen peroxide is scavenged by ascorbate-specific peroxidase in spinach chloroplasts. Plant Cell Physiol. 1981, 22, 867-880.

70. Mavis, R.D.; Stellwagen, E. Purification and subunit structure of glutathione reductase from bakers' yeast. Int. J. Biol. Chem. 1968, 243, 809-814. [CrossRef] 